\title{
Using biomass for climate change mitigation and oil use reduction
}

\author{
L. Gustavsson*, J. Holmberg, V. Dornburg, R. Sathre, T. Eggers, K. Mahapatra, G. Marland \\ Ecotechnology, Mid Sweden University, 83125 Östersund, Sweden
}

Received 6 March 2007; accepted 22 May 2007

Available online 2 August 2007

\begin{abstract}
In this paper, we examine how an increased use of biomass could efficiently meet Swedish energy policy goals of reducing carbon dioxide $\left(\mathrm{CO}_{2}\right)$ emissions and oil use. In particular, we examine the trade-offs inherent when biomass use is intended to pursue multiple objectives. We set up four scenarios in which up to $400 \mathrm{PJ} /$ year of additional biomass is prioritised to reduce $\mathrm{CO}_{2}$ emissions, reduce oil use, simultaneously reduce both $\mathrm{CO}_{2}$ emission and oil use, or to produce ethanol to replace gasoline. Technologies analysed for using the biomass include the production of electricity, heat, and transport fuels, and also as construction materials and other products. We find that optimising biomass use for a single objective (either $\mathrm{CO}_{2}$ emission reduction or oil use reduction) results in high fulfilment of that single objective (17.4 Tg C/year and $350 \mathrm{PJ}$ oil/year, respectively), at a monetary cost of 130-330 million $€$ /year, but with low fulfilment of the other objective. A careful selection of biomass uses for combined benefits results in reductions of $12.6 \mathrm{Tg} \mathrm{C} / \mathrm{year}$ and $230 \mathrm{PJ}$ oil/year ( $72 \%$ and $67 \%$, respectively, of the reductions achieved in the scenarios with single objectives), with a monetary benefit of 45 million $€ /$ year. Prioritising for ethanol production gives the lowest $\mathrm{CO}_{2}$ emissions reduction, intermediate oil use reduction, and the highest monetary cost.
\end{abstract}

(C) 2007 Elsevier Ltd. All rights reserved.

Keywords: Biomass; Climate change mitigation; Oil use reduction

\section{Introduction}

With increasing concern about energy security, energy cost, and the impact of energy systems on the global climate, many countries have adopted energy policies that aim to confront these issues. Sweden's national energy policy strives to create a sustainable energy system, with a long-term vision for Sweden to obtain all of its energy supply from renewable sources (Swedish Government, 2007). Elements of this policy include ensuring a reliable energy supply, increasing the efficiency of energy use, reducing the environmental impacts of energy use, breaking dependence on oil, and encouraging costeffectiveness in energy supply and use. Recently, the Swedish government has set a target of reducing, by the year 2020 , the use of oil in road transport by $40-50 \%$, in industry by $25-40 \%$, and in building heating by $100 \%$ (Commission on Oil Independence, 2006). The European

\footnotetext{
${ }^{*}$ Corresponding author.

E-mail address: leif.gustavsson@miun.se (L. Gustavsson).
}

Union (EU) also explicitly discusses energy security as a main concern of its energy policy and aims to address this concern by reducing energy demand, diversifying the sources of energy supply, and increasing reliance on internal sources of supply (EC, 2000). The EU has developed a strategy to increase the use of renewable energy resources (EC, 1997), including the use of biofuels in the transport sector (EU, 2003) and a biomass action plan (EC, 2005).

Biofuels play a significant role in the Swedish energy policy (Swedish Government, 2007), yet biomass produced in one country can be traded and used in another country. On the global scale, the various regions of the world have vastly different demands for, and potentials to supply, biomass. Fischer and Schrattenholzer (2001) estimated the total, global bioenergy potential for crop residues, biomass from grasslands, and wood and forest residues at $225,000 \mathrm{PJ}$ in 1990. A review of various studies (Berndes et al., 2003) showed that the estimated global potential of bioenergy varied widely between 30,000 and $340,000 \mathrm{PJ} /$ year (in 2020-2030), depending on assumptions made 
regarding land availability and cultivated species. Within the EU $2900 \mathrm{PJ}$ of bioenergy were used in 2003, while the potential of biomass for energy is estimated to be about $7900 \mathrm{PJ} /$ year by 2010 (EC, 2005). Intra-European trade in biomass is expanding and will likely continue to expand. While Sweden is a net exporter of woodbased products (Skogsstyrelsen, 2006), the EU-25 is in general a net importer. Intercontinental trade of biomass for energy, for example, wood pellets from Canada and ethanol from Brazil, is already occurring and is expected to increase.

Designing a national strategy aimed at expanding the use of biomass energy involves boundary conditions beyond those linked to techno-economic aspects of energy systems. It includes policy priorities, short- and long-term goals, available biomass potential, possibilities for technological development, the economic situation, and identification of niche markets and opportunities for added value. Strategy development becomes more difficult as the system becomes more complex and the number of actors increases, but regional and international perspectives are important when developing national strategies because additional opportunities may arise, and implementation priorities may shift, as the geographic scale of analysis becomes larger. Nevertheless, detailed energy policy is implemented at the national level, and commitments to international agreements such as the Kyoto Protocol exist at the national level.

Recent studies have recognised that the Swedish production of biomass for energy could be significantly increased (Börjesson et al., 1997; Hagström, 2006; Commission on Oil Independence, 2006). The amount of increased production would depend on, inter alia, forest management intensity (including fertilisation), recovery of forest biomass residues (including thinning residues, harvest slash, and stumps), the use of fallow land for biofuel cultivation, the selection of species to be cultivated, the level of wood products manufactured and the recovery of associated by-products, and the recovery of post-consumer wood waste (including demolition residues). In 2004, about $400 \mathrm{PJ}$ of biomass were used in the Swedish energy sector (STEM, 2005). Börjesson et al. (1997) estimated that in the long run it is possible to produce in Sweden a total of up to $820 \mathrm{PJ} /$ year of biomass through intensive management in forestry and agriculture, including energy crop cultivation on set-aside land. The Commission on Oil Independence (2006) estimates that Swedish biomass production for energy could be twice as large as today by 2050 , or about $800 \mathrm{PJ} /$ year.

In this study, we consider various ways to use up to $400 \mathrm{PJ} /$ year of additional biomass in Sweden, corresponding to a total Swedish biomass use of up to $800 \mathrm{PJ} /$ year. The biomass use options are analysed in a Swedish context, while acknowledging that the Swedish energy system is linked in many ways to regional and global systems.

\section{Aim}

Biomass is renewable, if properly managed, and biomass energy has net emissions of $\mathrm{CO}_{2}$ to the atmosphere only to the extent that fossil fuels are used in operation of the system. Sustainably managed biomass systems recycle the carbon that is taken in by photosynthesis and return it to the atmosphere during combustion. The net effect is that solar energy is used to provide energy services, and plants provide energy concentration and storage in chemical bonds.

Biomass is a limited resource and in many applications it is currently more expensive than fossil fuels, at least if climate change and energy security benefits are not considered. To use biomass energy as inexpensively as possible will facilitate an expansion of its use, and to use it as efficiently as possible will increase the impact of its use on achieving policy objectives. That is, if biomass is to be used in place of fossil fuels, it should be done in the applications where it most effectively serves society's objectives. The choice of biomass energy systems, and the parameters chosen for comparing them, will vary according to the objectives of the analysis. For example, greenhouse gas benefits of biomass use can be optimised with respect to any of several limiting factors, including per ton of biomass feedstock, per hectare of land, per unit of monetary resources spent for carbon emission reduction, or per unit of bioenergy output that can be absorbed by a specific market or sector (Schlamadinger et al., 2005). Regardless of the factor to be optimised, it has become widely accepted to include the full chain of biomass use within the analytical system boundaries, from primary plant growth to final fuel consumption (Schlamadinger et al., 1997).

There has been growing interest in efficient ways to use biomass for the substitution of fossil fuels and non-biomass materials, and many studies have compared the substitution efficiency of various technologies (see Section 4). In this paper, we apply these data to construct a nationalscale analysis of how biomass could be used efficiently to meet the two objectives of reducing $\mathrm{CO}_{2}$ emissions and oil use, considering monetary, primary energy, and biomass costs. We focus particularly on the compatibility of the multiple objectives and the trade-offs to be encountered in pursuing multiple objectives. Our primary focus is on the single country of Sweden, but we acknowledge that Sweden exists in a global energy market. We do not specifically address the efficiency of energy use at final demand, although it is clear that biomass can meet a larger fraction of total demand if that total demand is reduced. Our analysis is based on a review of techno-economic studies concerning various biomass options in the context of boundary conditions that apply to Sweden. Our goal is to better understand how a potentially important energy resource - biomass - can be used efficiently to satisfy the multiple objectives of energy policy. 


\section{Methods}

\subsection{Methodological framework}

We begin with a technologic-economic survey of different options for using biomass, using common system assumptions to allow comparison among the options. We consider state-of-the art technologies, or technologies that could be commercialised in the short term. We then evaluate the potential use of the different biomass options within the Swedish context. The options considered for increased use of biomass are electricity and heat production including in combined heat and power (CHP) plants, liquid transport fuels, building construction, iron production, and co-production of electricity and refined fuels in pulp mills.

We calculate six indices for each of the various options for using biomass. Three of the indices compare the options in terms of their effectiveness in reducing $\mathrm{CO}_{2}$ emission:

- Monetary cost of $\mathrm{CO}_{2}$ mitigation ( $€ / \mathrm{CO}_{2}$ avoided).

- Primary energy cost of $\mathrm{CO}_{2}$ mitigation (GJ primary energy $/ \mathrm{CO}_{2}$ avoided).

- Biomass cost of $\mathrm{CO}_{2}$ mitigation (GJ biomass $/ \mathrm{CO}_{2}$ avoided).

These indices express, respectively, the economic, the primary energy, and the biomass use efficiency of reducing $\mathrm{CO}_{2}$ emissions. Primary energy use is defined here as the total amount of energy in basic forms (e.g. coal, crude oil, biomass) needed to produce a final energy service, after taking into account losses from extraction, conversion, and transport and distribution. Similarly, we use three indices to compare the effectiveness of the biomass options in reducing oil use:

- Monetary cost of reduced oil use ( $€ / G J$ oil reduced).

- Primary energy cost of reduced oil use (GJ primary energy/GJ oil reduced).

- Biomass cost of reduced oil use (GJ biomass/GJ oil reduced).

These three indices recognise that the provision of oil products is a principal concern with respect to energy security, even though Sweden and many other countries of the EU are also reliant on imports of coal, natural gas, and even biomass fuels. Given the limited nature of the biomass resource, we place particular emphasis on indices 3 and 6 in the list above, the amount biomass required to avoid a unit of $\mathrm{CO}_{2}$ emissions and a unit of oil use, respectively.

The trade-offs that may exist in attempting to reduce $\mathrm{CO}_{2}$ emission and reduce oil use, individually, and jointly, are then analysed. For this purpose, we set up scenarios in which biomass is used primarily to reduce either $\mathrm{CO}_{2}$ emissions or the use of oil. We also seek biomass uses that simultaneously reduce both $\mathrm{CO}_{2}$ emissions and oil use. As the production of ethanol for use in the transport sector to reduce oil imports and $\mathrm{CO}_{2}$ emissions is an option that is being politically discussed in Sweden, we include a scenario in which biomass is used intensively to produce ethanol for transport fuels. Thus, the four scenarios described here are

1. $\mathrm{CO}_{2}$ emission reduction scenario-to mitigate climate change,

2. oil use reduction scenario - to reduce oil dependence,

3. combined scenario - reducing both $\mathrm{CO}_{2}$ emissions and oil use, and

4. ethanol scenario- using biomass to produce ethanol for use as transport fuel.

We concentrate on the use of additional biomass, biomass that is potentially available but is not currently used for energy or material purposes. Thus, based on options available at the national level, we discuss how increased Swedish biomass production of up to $400 \mathrm{PJ} /$ year could be used to reduce $\mathrm{CO}_{2}$ emissions and oil use.

\subsection{Basic assumptions}

Obtaining and using biomass and fossil fuels requires energy input for processing and transport. The relevant characteristics of various forms of biomass production, and of the fossil fuels, are summarised in Table 1. In our scenario calculations, we base $\mathrm{CO}_{2}$ emissions, oil use, and primary energy use for obtaining biomass on a mixture of biomass sources including short rotation forestry, thinning and harvest residues from conventional forestry, stumps, processing residues, and post-consumer wood such as demolition residues (see Table 1). The actual mixture of biomass sources may be different from that assumed here, but this would have minimal impact on the overall results. Wood density is assumed to be $400 \mathrm{~kg}$ dry matter $/ \mathrm{m}^{3}$. The moisture content and lower heating value of fresh biomass are, respectively, assumed to be $60 \%$ and $15.3 \mathrm{GJ} /$ tonne dry matter.

We assume that the marginal electricity is coal fired, i.e. that incremental use or savings of electricity will be of electricity from a coal-fired steam condensing plant. Marginal electricity production in Swedish analyses is generally considered to be Danish coal-fired plants, although natural gas could also be considered as a marginal fuel (see Section 7.2). The use or replacement of fossil fuels impacts $\mathrm{CO}_{2}$ emissions, oil use, and primary energy use. Data on these aspects of reference fossil-energy carriers (Table 1) are based on life-cycle analyses and are derived from UBA (2006). The base year for costs, energy use, and emissions is 2003, the latest year for which complete data are available.

The costs of oil-based energy carriers are based on a crude oil price of $40 \mathrm{US} \$ / \mathrm{bbl}$. The prices of gasoline, diesel, and heavy and light fuel oils are assumed to be coupled to crude oil prices. The ratio of gasoline and diesel prices to 
Table 1

$\mathrm{CO}_{2}$ emission, oil use, primary energy use, and monetary cost for biomass sources and reference fossil-energy carriers

\begin{tabular}{|c|c|c|c|c|c|}
\hline Source & Description & $\begin{array}{l}\mathrm{CO}_{2} \text { emission } \\
(\mathrm{kg} \mathrm{C})\end{array}$ & $\begin{array}{l}\text { Oil use } \\
\text { (GJ oil) }\end{array}$ & $\begin{array}{l}\text { Primary energy use }{ }^{a} \\
\left(G J_{\text {primary }}\right)\end{array}$ & $\begin{array}{l}\text { Monetary cost } \\
\left(€_{2003}\right)\end{array}$ \\
\hline \multicolumn{6}{|l|}{ Biomass } \\
\hline Short rotation forestry $(1,2)$ & Production and transport & 0.86 & 0.021 & 0.046 & 3.2 \\
\hline Thinning residues $(1,3)$ & Recovery and transport & 0.94 & 0.043 & 0.047 & 3.8 \\
\hline Harvest residues $(1,3)$ & Recovery and transport & 0.78 & 0.034 & 0.039 & 3.8 \\
\hline Stumps (4) & Recovery and transport & 0.55 & 0.026 & 0.025 & 4.0 \\
\hline Processing residues (5) & Recovery and transport & 0.22 & 0.010 & 0.011 & 3.3 \\
\hline Demolition residues (5) & Recovery and transport & 0.22 & 0.010 & 0.011 & 2.2 \\
\hline $\begin{array}{l}\text { Mixture of biomass sources used in this } \\
\text { study }{ }^{b}\end{array}$ & & 0.68 & 0.026 & 0.035 & 3.4 \\
\hline \multicolumn{6}{|l|}{ Fossil } \\
\hline Coal $(6,7)$ & Anthracite, import Sweden & 29.2 & 0.00 & 0.12 & 2.0 \\
\hline Oil $(6,7)$ & Crude oil mix Sweden & 20.8 & 1.00 & 0.03 & 6.4 \\
\hline Natural gas $(6,7)$ & Natural gas mix Sweden & 15.6 & 0.00 & 0.01 & 5.1 \\
\hline Diesel $(7,8)$ & Refinery & 21.7 & 1.03 & 0.10 & 8.4 \\
\hline Gasoline $(7,8)$ & Refinery & 24.0 & 1.14 & 0.20 & 8.4 \\
\hline Light fuel oil $(7,9)$ & Refinery & 21.9 & 1.04 & 0.10 & 6.4 \\
\hline Heavy fuel oil $(7,9)$ & Refinery & 23.1 & 1.08 & 0.10 & 4.5 \\
\hline Electricity from coal (10) & Steam-turbine (eff. $40 \%$ ) & 72.9 & 0.00 & 1.80 & 10.1 \\
\hline
\end{tabular}

All numbers are per GJ of energy carrier.

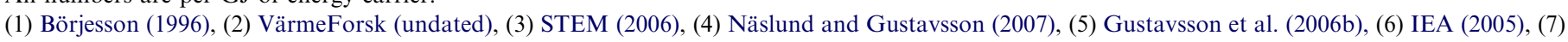
UBA (2006), (8) JRC (2005), (9) STEM (2004), (10) STEM (2003).

${ }^{\text {a }}$ Primary energy values do not include the feedstock energy of the fuel or electricity itself.

${ }^{\mathrm{b}}$ Assuming a mixture of $30 \%$ short rotation forestry, $20 \%$ thinning residues, $20 \%$ harvest residues, $5 \%$ stumps, $10 \%$ processing residues, and $15 \%$ demolition residues.

crude oil price is assumed to be 1.3 (JRC, 2005). The ratios of heavy and light fuel oil prices to crude oil price are assumed to be 0.7 and 1.0 , respectively (STEM, 2004). The production cost for coal-based electricity includes depreciation of capital.

Cost calculations of the biomass use options and the fossil reference systems are based on both investment and operating costs. Transaction costs are not included, and we do not consider the effects of energy or carbon taxes. ${ }^{1} \mathrm{~A}$ lifetime of 25 years for CHP and power plants and 15 years for other technologies is assumed. Monetary costs are calculated with an interest rate of $6 \%$. Costs depend to a large extent on whether or not investments in biomassbased technologies are made instead of investments in conventional technology. If the investment in biomass technology is considered to be additional, e.g. replacing an installation that would not otherwise be replaced, then at least part of the installation cost has to be accounted for in the mitigation cost, depending on the remaining lifetime of the existing fossil technology. Since our study has a long time-scope, we assume that investments in biomass

\footnotetext{
${ }^{1}$ In Sweden, carbon taxes are applied to $\mathrm{CO}_{2}$ emissions, and energy taxes are applied to the use of particular forms of energy. The mitigation costs calculated in this analysis are the direct costs required to avoid a unit of $\mathrm{CO}_{2}$ emission or oil use. If a carbon or oil tax is included in the analysis, the mitigation costs would be the direct costs minus the avoided tax.
}

technologies are made when old fossil equipment would have to be replaced or retrofitted in any event. Consequently, we account for the cost difference between the fossil and the biomass technologies, including the full investment costs for both systems. If the fossil investment were not fully considered, the mitigation cost would be higher.

\subsection{Decision making with multiple objectives}

In a multi-objective decision situation in the absence of uncertainty we often search for pareto optimal solutions (Winston, 1994). A solution is pareto optimal if there is no other solution that is at least as good with respect to every objective and better with respect to at least one objective. In general, there are infinitely many pareto optimal solutions. A common approach to single-objective problems is optimisation by linear programming. Linear programming can also be used to identify a set of pareto optimal solutions in a multiple-objective problem. Choosing between different pareto optimal solutions may involve, for example, weighting of objectives, definition of acceptable levels, ranking of the importance of the objectives, definition of targets, and assignment of distance measures for each option relative to the target (Hobbs and Meier, 2003). In any case, the choice between pareto optimal solutions requires some form of valuation. How different 
objectives are valued will depend on the priorities, risk aversion, etc. of individual decision makers.

Optimisation is inherently difficult in problems subjected to large uncertainties, since the optimal solution may vary largely depending on the assumptions made. Least-cost optimisation under uncertain external costs is one such example (Gustavsson and Karlsson, 2006). In the present study, we apply an approach that combines weighting of attributes with exogenous constraints that appears practically attractive (Section 6.4). Preliminary comparison to optimisation by linear programming shows that the resulting scenarios are close to pareto optimal, under the assumptions used.

\section{Efficiency of biomass substitution}

Here, we discuss the various technological options for using biomass in place of fossil fuels and non-biomass materials, and we calculate parameter values for $\mathrm{CO}_{2}$ emission and oil use reductions in terms of monetary cost, primary energy cost, and biomass cost.

\subsection{Electricity and heat}

Biomass can be used to produce electricity and/or heat and as such can substitute for fossil fuels for the production of electricity and/or heat. The efficiency of this substitution with regard to $\mathrm{CO}_{2}$ emission and oil use reduction will depend on the biomass conversion technologies chosen and on the reference energy systems for which they substitute. Substitution is regarded on a system level, i.e. biomass heat and/or power production replaces a fossil option with similar output. A variety of technology choices is possible for the investigation of biomass energy as well as for the fossil options to be displaced. Here, we have analysed a number of technologies to produce heat, CHP, and electricity from biomass, listed in Table 2. In each case, we have paired these technologies with comparable technologies to produce heat and/or electricity from coal, natural gas or oil. ${ }^{2}$ Data on the reference heat and power plants include oil used and $\mathrm{CO}_{2}$ emitted during the production and delivery of the energy carrier, and are based on a similar technology level as the biomass system (UBA, 2006). The production costs of the biomass and fossil systems are determined from fuel costs and investment and operating costs (see Section 3.2). An overview of efficiencies and costs used in this study is given in the appendix (Tables A1 and A2). The results of the

\footnotetext{
${ }^{2}$ The biomass CHP plants are compared to coal or natural gas-fired CHP plant or to an oil-based heat plant plus an oil-based power plant, as oil-based CHP plants are uncommon. Also, the biomass CHP plants are compared to resistance heating with coal-fired electricity. In each case, the amount of heat produced is the same for the biomass plant and for the fossil option. When a biomass CHP plant is compared with resistance heating, excess electricity production is assumed to replace electricity produced in a stand-alone coal-fired power plant.
}

comparisons between biomass plants and fossil reference plants are presented in Table 2 .

\subsection{Transport fuels}

A broad variety of bio-based transport fuels exists, see e.g. JRC (2005). Here, we select liquid transport fuels that can be produced from lignocellulosic biomass with technologies available in the short term. Di-methyl-ether (DME) and Fischer-Tropsch (FT) diesel are used to replace diesel, while ethanol and methanol are used to replace gasoline.

Data on the energy efficiency and costs of ethanol, FTdiesel, and methanol production are derived from Hamelinck and Faaij (2006), while data on the energy efficiency and costs of DME production are from Bio-DME Consortium (2002). The fuel economy is different for different fuel/engine combinations. Alcohols may have a higher efficiency than gasoline in spark-ignition engines, but estimates of the magnitude of the advantage vary (Ahlvik and Brandberg, 2001; Hamelinck and Faaij, 2006; Maclean and Lave, 2000, 2003). We apply correction factors based on intermediate values. Efficiency differences found for different fuels in compression-ignition (diesel) engines are small (Hamelinck and Faaij, 2006) and are disregarded here. Results for the production of biofuels are presented in Table 2, while detailed data for the calculations are shown in Table A3.

\subsection{Wood construction}

Increasing the use of wood material in construction is an option for reducing $\mathrm{CO}_{2}$ emissions and oil use. Producing wood construction materials uses less energy and results in lower net $\mathrm{CO}_{2}$ emission than using materials such as reinforced concrete (Börjesson and Gustavsson, 2000; Gustavsson and Sathre, 2006). In this study, wood usage is compared to a reference scenario in which reinforced concrete is used as building material. Calculations are based on a case study of a multi-story apartment building constructed in Sweden using wood structural framing, compared to a functionally equivalent building constructed with a reinforced concrete frame (Gustavsson et al., 2006b). The comparison is made on a building level, and all materials composing the two buildings are included in the calculations. The reductions in net $\mathrm{CO}_{2}$ emission and oil use, over the building lifecycle, per unit of additional wood needed to make the wood-frame building, are calculated. The oil reduction cost takes into account oilbased fuels used for the manufacture and transport of materials for the two versions of the building. The $\mathrm{CO}_{2}$ reduction cost takes into account emissions from fossil fuel combustion for material processing and logistics, the reduction of emissions due to replacing fossil fuel with biomass residues, the avoided emissions due to cement process reactions, and the carbon stock change in wood materials. 
Table 2

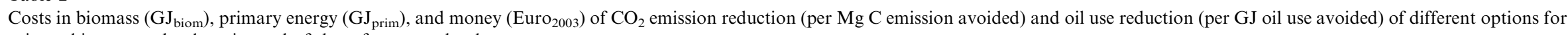
using a biomass technology instead of the reference technology

\begin{tabular}{|c|c|c|c|c|c|c|c|c|c|}
\hline $\begin{array}{l}\text { Ref. } \\
\text { no. }\end{array}$ & $\begin{array}{l}\text { Reference fossil } \\
\text { technology }\end{array}$ & Biomass technology & $\begin{array}{l}\text { Biomass cost per } \\
\text { carbon avoided } \\
(\mathrm{GJ} \text { biom } / \mathrm{Mg} \mathrm{C})\end{array}$ & $\begin{array}{l}\text { Primary energy cost } \\
\text { per carbon avoided } \\
\text { (GJ prim/Mg C) }\end{array}$ & $\begin{array}{l}\text { Monetary cost } \\
\text { per carbon avoided } \\
\text { (Euro/Mg C) }\end{array}$ & $\begin{array}{l}\text { Biomass cost } \\
\text { per oil avoided } \\
\text { (GJ biom/GJ oil) }\end{array}$ & $\begin{array}{l}\text { Primary energy cost } \\
\text { per oil avoided } \\
\text { (GJ prim/GJ oil) }\end{array}$ & $\begin{array}{l}\text { Monetary cost } \\
\text { per oil avoided } \\
\text { (Euro/GJ oil) }\end{array}$ & $\begin{array}{l}\text { Total } \\
\text { potential } \\
\text { (PJ biomass) }\end{array}$ \\
\hline \multicolumn{10}{|c|}{ Small-scale heat } \\
\hline $\mathrm{S} 1$ & $\begin{array}{l}\text { Small-scale oil } \\
\text { boiler }\end{array}$ & Pellet boiler & 68.0 & 17.3 & -37.2 & 1.4 & 0.3 & -0.7 & 29.94 \\
\hline $\mathrm{S} 2$ & $\begin{array}{l}\text { Small-scale gas } \\
\text { boiler }\end{array}$ & Pellet boiler & 107.7 & 38.2 & -12.8 & $\mathrm{~N} / \mathrm{A}$ & $\mathrm{N} / \mathrm{A}$ & $\mathrm{N} / \mathrm{A}$ & 0.80 \\
\hline $\mathrm{S} 3$ & $\begin{array}{l}\text { Electric } \\
\text { resistance } \\
\text { heating }\end{array}$ & Pellet boiler & 19.3 & -18.9 & -53.1 & $\mathrm{~N} / \mathrm{A}$ & $\mathrm{N} / \mathrm{A}$ & $\mathrm{N} / \mathrm{A}$ & 36.38 \\
\hline S4 & Electric boiler & Pellet boiler & 18.9 & -19.3 & -2.1 & $\mathrm{~N} / \mathrm{A}$ & $\mathrm{N} / \mathrm{A}$ & $\mathrm{N} / \mathrm{A}$ & 35.23 \\
\hline S5 & $\begin{array}{l}\text { Small-scale oil } \\
\text { boiler }\end{array}$ & $\begin{array}{l}\text { Heat pump with bio- } \\
\text { electricity }\end{array}$ & 27.9 & -21.6 & -164.9 & 0.6 & -0.5 & -3.7 & 14.05 \\
\hline S6 & $\begin{array}{l}\text { Small-scale gas } \\
\text { boiler }\end{array}$ & $\begin{array}{l}\text { Heat pump with bio- } \\
\text { electricity }\end{array}$ & 41.1 & -23.0 & -205.5 & $\mathrm{~N} / \mathrm{A}$ & $\mathrm{N} / \mathrm{A}$ & $\mathrm{N} / \mathrm{A}$ & 0.37 \\
\hline S7 & $\begin{array}{l}\text { Electric } \\
\text { resistance } \\
\text { heating }\end{array}$ & $\begin{array}{l}\text { Heat pump with bio- } \\
\text { electricity }\end{array}$ & 8.7 & -29.6 & -92.4 & $\mathrm{~N} / \mathrm{A}$ & $\mathrm{N} / \mathrm{A}$ & $\mathrm{N} / \mathrm{A}$ & 17.08 \\
\hline S8 & Electric boiler & $\begin{array}{l}\text { Heat pump with bio- } \\
\text { electricity }\end{array}$ & 8.5 & -29.8 & -42.6 & $\mathrm{~N} / \mathrm{A}$ & $\mathrm{N} / \mathrm{A}$ & $\mathrm{N} / \mathrm{A}$ & 16.54 \\
\hline S9 & $\begin{array}{l}\text { Small-scale oil } \\
\text { boiler }\end{array}$ & DH-BIG/CC CHP & 25.3 & -15.3 & 14.7 & 2.7 & -1.6 & 1.6 & 58.38 \\
\hline S10 & $\begin{array}{l}\text { Small-scale gas } \\
\text { boiler }\end{array}$ & DH-BIG/CC CHP & 27.3 & -15.1 & 21.7 & $\mathrm{~N} / \mathrm{A}$ & $\mathrm{N} / \mathrm{A}$ & $\mathrm{N} / \mathrm{A}$ & 1.56 \\
\hline S11 & $\begin{array}{l}\text { Electric } \\
\text { resistance } \\
\text { heating }\end{array}$ & DH-BIG/CC CHP & 17.1 & -21.2 & -9.4 & $\mathrm{~N} / \mathrm{A}$ & $\mathrm{N} / \mathrm{A}$ & $\mathrm{N} / \mathrm{A}$ & 70.95 \\
\hline $\mathrm{S} 12$ & Electric boiler & DH-BIG/CC CHP & 16.9 & -21.3 & 13.6 & $\mathrm{~N} / \mathrm{A}$ & $\mathrm{N} / \mathrm{A}$ & $\mathrm{N} / \mathrm{A}$ & 68.71 \\
\hline \multicolumn{10}{|c|}{ Medium-scale heat } \\
\hline M1 & Oil boiler & $\begin{array}{l}\text { Medium-scale wood } \\
\text { boiler }\end{array}$ & 50.1 & -0.1 & -4.6 & 1.0 & 0.0 & -0.1 & 19.30 \\
\hline M2 & Gas boiler & $\begin{array}{l}\text { Medium-scale wood } \\
\text { boiler }\end{array}$ & 74.0 & 10.4 & 68.3 & $\mathrm{~N} / \mathrm{A}$ & $\mathrm{N} / \mathrm{A}$ & $\mathrm{N} / \mathrm{A}$ & 3.45 \\
\hline $\mathrm{m} 3$ & Oil boiler & DH-BIG/CC CHP & 25.1 & -15.7 & 11.2 & 2.5 & -1.6 & 1.1 & 44.34 \\
\hline $\mathrm{m} 4$ & Gas boiler & DH-BIG/CC CHP & 27.1 & -15.2 & 26.0 & $\mathrm{~N} / \mathrm{A}$ & $\mathrm{N} / \mathrm{A}$ & $\mathrm{N} / \mathrm{A}$ & 7.92 \\
\hline $\mathrm{m} 5$ & $\begin{array}{l}\text { Electric } \\
\text { resistance } \\
\text { heating }\end{array}$ & DH-BIG/CC CHP & 17.1 & -21.2 & -55.8 & $\mathrm{~N} / \mathrm{A}$ & $\mathrm{N} / \mathrm{A}$ & $\mathrm{N} / \mathrm{A}$ & 23.94 \\
\hline $\mathrm{m} 6$ & Electric boiler & DH-BIG/CC CHP & 16.9 & -21.3 & -32.4 & $\mathrm{~N} / \mathrm{A}$ & $\mathrm{N} / \mathrm{A}$ & $\mathrm{N} / \mathrm{A}$ & 11.98 \\
\hline \multicolumn{10}{|c|}{ Industrial heat/steam } \\
\hline il & $\begin{array}{l}\text { Process heat, oil } \\
\text { boiler }\end{array}$ & $\begin{array}{l}\text { Industrial wood } \\
\text { boiler }\end{array}$ & 45.8 & -1.7 & 19.6 & 1.0 & 0.0 & 0.4 & 9.44 \\
\hline i2 & $\begin{array}{l}\text { Industrial space } \\
\text { heating, oil }\end{array}$ & $\begin{array}{l}\text { Medium-scale wood } \\
\text { boiler }\end{array}$ & 50.7 & 0.4 & -4.7 & 1.0 & 0.0 & -0.1 & 16.00 \\
\hline
\end{tabular}




$\begin{array}{llll}\text { d1 } & \begin{array}{lll}\text { Heat plant base- } \\ \text { load oil }\end{array} & \text { DH BIG/CC CHP } & 24.4 \\ \text { d2 } & \text { DH gas CHP } & \text { DH BIG/CC CHP } & 53.9 \\ \text { d3 } & \text { DH coal CHP } & \text { DH BIG/CC CHP } & 26.4 \\ \text { d4 } & \begin{array}{l}\text { Heat plant peak- } \\ \text { load oil }\end{array} & \text { Wood-powder burner } & 72.5 \\ & & \end{array}$

\begin{tabular}{|c|c|c|c|c|c|}
\hline-16.8 & -31.0 & 2.1 & -1.5 & -2.7 & 5.11 \\
\hline-5.3 & 20.7 & $\mathrm{~N} / \mathrm{A}$ & $\mathrm{N} / \mathrm{A}$ & $\mathrm{N} / \mathrm{A}$ & 13.94 \\
\hline-9.4 & -14.6 & N/A & $\mathrm{N} / \mathrm{A}$ & $\mathrm{N} / \mathrm{A}$ & 17.18 \\
\hline 19.5 & 109.9 & 1.2 & 0.3 & 1.9 & 11.90 \\
\hline-8.6 & -109.3 & 0.9 & -0.2 & -2.3 & 7.99 \\
\hline-6.5 & 79.5 & $\mathrm{~N} / \mathrm{A}$ & $\mathrm{N} / \mathrm{A}$ & $\mathrm{N} / \mathrm{A}$ & 5.89 \\
\hline 29.1 & 334.4 & 2.1 & 0.8 & 9.2 & 411.30 \\
\hline 26.4 & 125.6 & 1.3 & 0.4 & 2.1 & 259.25 \\
\hline 47.7 & 494.1 & 1.6 & 0.7 & 7.7 & 219.37 \\
\hline 34.0 & 294.2 & 2.1 & 0.9 & 7.7 & 289.96 \\
\hline-9.6 & -789.0 & 6.8 & -4.0 & -331.1 & 1.45 \\
\hline 4.3 & 199.7 & $\mathrm{~N} / \mathrm{A}$ & $\mathrm{N} / \mathrm{A}$ & $\mathrm{N} / \mathrm{A}$ & 61.24 \\
\hline-22.3 & -20.5 & $\mathrm{~N} / \mathrm{A}$ & $\mathrm{N} / \mathrm{A}$ & $\mathrm{N} / \mathrm{A}$ & 23.17 \\
\hline 86.1 & -20.0 & 1.0 & 0.5 & -0.1 & 75.38 \\
\hline 30.7 & -83.8 & 0.8 & 0.3 & -0.7 & 77.97 \\
\hline 22.7 & 45.3 & 1.3 & 0.4 & 0.8 & 8.27 \\
\hline
\end{tabular}

Electric power only

e2

Power plant coal Power-BIG/CC

41.6

31.6

Ethanol

Transport fuels
$\mathrm{t} 1 \quad$ Gasoline

t2 Gasoline

Diesel

Methanol

Diesel

DME

FT-Diesel

76.1
79.6
102.4

79.6

102.4

Building material

b1 Concrete-

Wood-frame building

16.1 buildin

cl Metallurgy coke Charcoal 40

Pulp and paper, BLG

Power plant coal BLGCC

p2 Diesel

BLG DME

Gasoline BLG Methanol

15.6

Pulp and paper, Lime kiln fuel switch

98.4

74.7

22.7

45.3

1.3

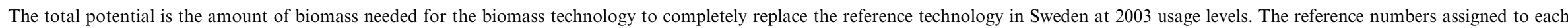
technology correspond to the numbers in Figs. 2-5. "N/A" means that the index is not applicable because no oil use is avoided.

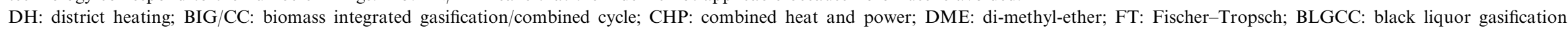
combined cycle. 
Primary energy used for production of materials is shown in Table A4. As we consider all biomass flows associated with the building construction to be part of the system, the biomass residues from the harvest, processing and demolition that are available for use outside of the production process are assumed to be used as biofuel to replace fossil fuel for electricity production; see Section 4.1. The 2003 monetary costs for construction of the wood- and concrete-framed buildings are estimated by adjusting the building costs at time of construction (Persson, 1998) with the building price index for multi-dwelling buildings in Sweden (Statistics Sweden, 2006a). The wood-frame building is approximately $€ 55,000$ less expensive than the concrete-frame version, so the monetary costs of $\mathrm{CO}_{2}$ and oil reduction are negative, i.e. there is a reduction in $\mathrm{CO}_{2}$ emissions, oil use, and cost. The results are shown in Table 2.

\subsection{Ferrous metallurgy industry}

The smelting of iron from ore is accomplished by mixing the ore with a solid, combustible, carbonaceous material that performs three functions: the combustion of the material raises the temperature of the ore; carbon from the material strips oxygen from the ore to yield elemental iron plus $\mathrm{CO}_{2}$; and the refractory strength of the material provides voids that allow gas permeability during smelting (Gupta, 2003). Charcoal made from biomass and coke made from coal are both suitable for use in iron production. Charcoal was long used to smelt iron and was gradually displaced by coke during recent centuries. In $1948,31 \%$ of Swedish pig iron was made using charcoal (FAO, 1964). No charcoal is used in Swedish iron and steel production now. In 2004 in Sweden, 4.1 Mtonne of crude steel were produced from ore (Jernkontoret, 2006), using 1.5 Mtonne of coke (Statistics Sweden, 2006b). Although the Swedish iron and steel industry is more efficient than the global average, production of iron from ore still emitted about $4.3 \%$ of total net Swedish $\mathrm{CO}_{2}$ emission in 2004 (SEPA, 2006b).

To calculate the $\mathrm{CO}_{2}$ and oil reduction efficiency of using charcoal for iron smelting, we assume that equal weights of charcoal and coke are equally effective in iron production (FAO, 1964). We assume a coal-to-coke conversion efficiency of $80 \%$ by dry weight (Eikeland et al., 2001), and a biomass-to-charcoal efficiency of 37\% (Antal et al., 1996). We assume that charcoal is made from primary roundwood because of the larger size of biomass raw material needed. The fossil carbon emissions from forestry operations are based on Berg and Lindholm (2005). Combustible gas is recovered from the coke oven (Diemer et al., 2004) and the charcoal retort (Eikeland et al., 2001). This gas is used to fire the coke oven and charcoal retort, respectively, and surplus gas is used to replace fossil fuel used for electricity production. Monetary costs for coke and charcoal are from Eikeland et al. (2001). The calculated monetary, primary energy, and biomass costs of $\mathrm{CO}_{2}$ emission and oil use reduction are shown in Table 2.

\subsection{Pulp industry}

The potential benefits of new technologies, including black liquor gasification (BLG), in a model pulp mill using modern, commercially available technology have been analysed by STFI (2003) and Berglin et al. (2003). Based on these results, we estimate the potential for increased production of electricity or transport fuels from biomass using BLG. The electricity is assumed to be produced using combined cycle technology, and transport fuels are assumed to be methanol or DME. The BLG system is compared with a conventional recovery boiler. The additional amount of biofuel needed to cover internal energy deficits due to exports of fuel or electricity depends on the energy balance of the reference mill and the changes induced by introduction of BLG. Model studies (STFI, 2003; Berglin et al., 2003) show that BLG with electricity production may, under certain conditions, increase the electricity surplus without the need for additional fuels. If transport fuel is produced instead, there will be a deficit of electricity and steam if the recovery boiler is fully replaced. If the pulp mill is integrated with a paper mill, the total energy demand will be higher and export of electricity or fuels will require input of additional biomass in any case. We assume that additional biomass will be required to cover a steam deficit for $75 \%$ of the black liquor if BLG is introduced. Use of black liquor and tall oil is aggregated in the statistics (Statistics Sweden, 2004c); we assume that $95 \%$ is black liquor.

The recovery boiler in a chemical pulp mill represents a large investment, and changes to the recovery system are likely to be done when the boiler needs to be replaced or retrofitted. Therefore, we base our calculations on the assumption that the existing recovery boiler is replaced also in the reference case.

Results for an integrated pulp and paper mill converted for BLG are presented in Table 2, and supporting data are shown in Table A5.

The switching of fuel for the lime kiln is another option for increased bioenergy use in sulphate pulp mills. The lime kiln is part of the chemical recovery cycle and is conventionally fired with oil. A few lime kilns have been successfully converted to biofuels (gasified or as dry powder) (Möllersten, 2002). Möllersten (2002) and references therein give estimates for total potential (1.0-1.2 TWh fuel oil substituted), incremental investment costs (0.5-0.6 million US\$/MW oil substituted), incremental operation and maintenance costs $(0.4$ million US\$/year excluding energy costs) for a biomass gasifier unit replacing an $11 \mathrm{MW}$ oil burner. Furthermore, an estimated 1.3-1.4 MW of biofuel and an additional $0.04 \mathrm{MW}$ electricity are needed to substitute $1 \mathrm{MW}$ of oil. In the present study, we assume that lime kilns are converted to biofuels, and use mean values from the cost and efficiency 


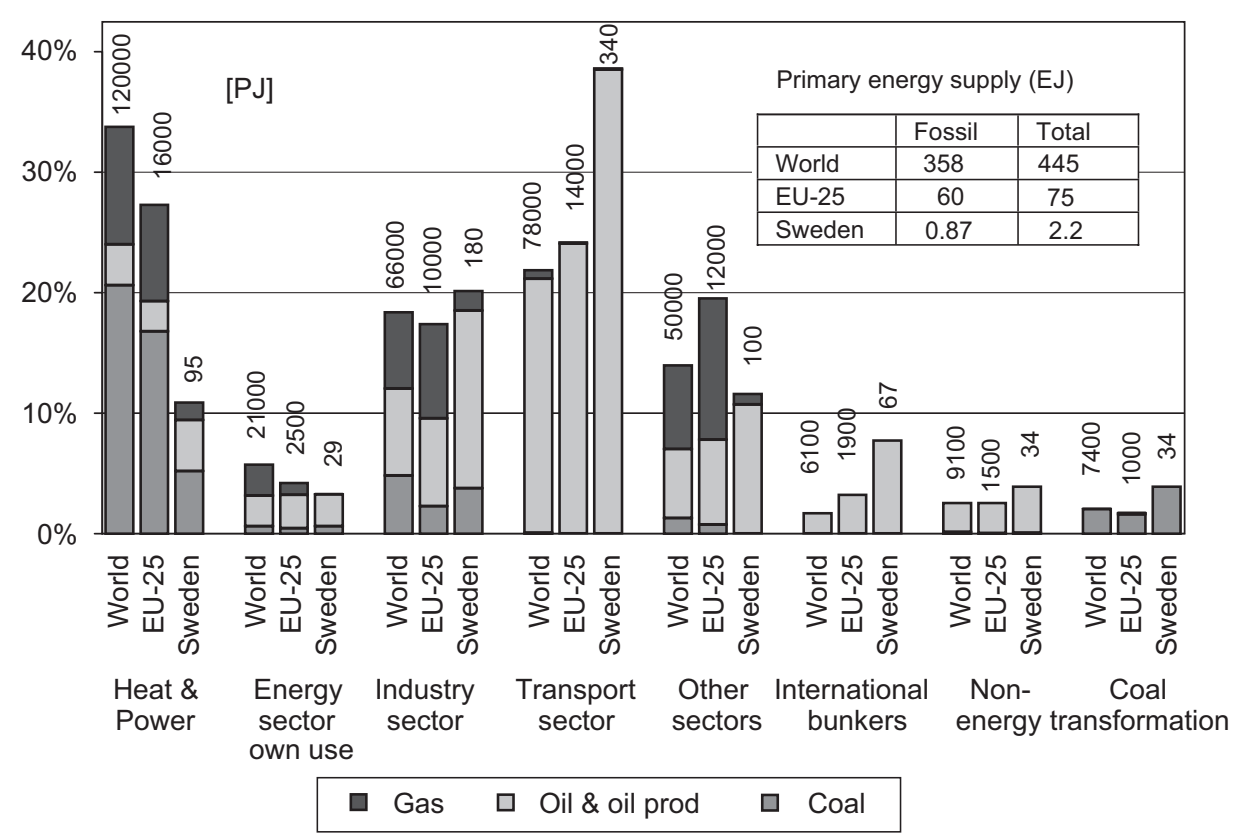

Fig. 1. Global, EU-25, and Swedish fossil fuel use in different sectors in 2003, as per cent of total fossil-fuel use. Absolute numbers (PJ) are shown above each bar, and totals are given in the inset box (IEA, 2005, 2006).

ranges given by Möllersten (2002). We assume that most of the $6 \mathrm{PJ}$ of oil reportedly used for direct heat generation (Wiberg, 2001) was used in lime kilns, and that $75 \%$ of this could be replaced with biomass fuel. The results are shown in Table 2.

\section{5. $\mathrm{CO}_{2}$ emission and oil dependence}

The Swedish energy supply differs significantly from the global and European energy supply (Fig. 1). Fossil fuels provide about $80 \%$ of global and EU primary energy supplies, but about $40 \%$ of the Swedish primary energy supply (IEA, 2005, 2006). Sweden produces large shares of electricity from nuclear and hydropower, and heat from biofuels. Hence, a higher proportion of fossil fuels is used in Sweden for transport and a lower proportion is used for heat and power.

Electricity production in the EU-25 is dominated by fossil thermal condensing plants, accounting for $57 \%$ of gross electricity supply, and nuclear power plants account for $31 \%$ (Eurostat, 2005), while about $10 \%$ of the electricity was co-generated with heat (Danko and Lösönen, 2006).

In the EU-25, oil accounts for about half of fossil fuel used, while coal and gas account for the remainder, the share of gas being slightly higher than that for coal. The trend is that natural gas is replacing coal over time (STEM, 2005). The EU-25 are strongly dependent on imports to meet their energy requirements, ${ }^{3}$ and this is forecast to continue if no measures are taken (EC, 2000).

\footnotetext{
${ }^{3}$ About $80 \%$ of the oil supplied to EU-15 in 2002 was imported, as was about $53 \%$ of the coal and $47 \%$ of the gas.
}

\subsection{Swedish energy supply and oil dependence}

The Swedish primary energy supply was 2158 PJ in 2003. Of this, $800 \mathrm{PJ}$ was imported fossil fuel. Most of the remainder, $1295 \mathrm{PJ}$, was supplied by hydropower, nuclear energy, and renewable combustibles and waste (IEA, 2006). Renewable sources accounted for some $25 \%$. Fossil-fuel use in Sweden is dominated by oil products, with smaller contributions from coal and gas (IEA, 2006). Excluding international bankers and non-energy use, the transport sector accounted for $44 \%$ of fossil-fuel use in 2003 , while $23 \%$ was used by industry and $12 \%$ in the heat and electricity sector. Historically, the supply of crude oil and oil products was reduced by more than $40 \%$ between 1970 and 2004, while total energy supply (imports minus exports plus domestic primary energy, as defined by UN/ ECE) increased by $42 \%$. During this period, however, final energy use increased by only $8 \%$. Hence, the energy efficiency of energy supply was reduced significantly.

Sweden is a net exporter or importer of electricity depending, inter alia, on the availability of water in hydropower reservoirs and on the temperature during the year. Hydropower and nuclear power provided an average of $46 \%$ and $43 \%$, respectively, of Swedish electricity generation during the years 2000-2003. Another 7\% of electricity was produced in CHP plants, of which $3 \%$ was in industrial plants (STEM, 2004). The marginal power production in the Nordic system, including Sweden, is mainly from Danish coal condensing power plants. In the future, the marginal electricity might be produced from natural gas in Norway (STEM, 2002a).

District heating accounts for some $47 \%$ of the space heating of residential and commercial premises in Sweden. 
It is the most common form of heating in apartment buildings. Oil (18 PJ), coal $(7.2 \mathrm{PJ})$, and natural gas (10.6 PJ) together accounted for $18 \%$ of the energy input to district heating in 2003, while biofuels, peat, refuse, etc. accounted for more than 60\% (STEM, 2004, 2005). The remainder was supplied by heat pumps and waste heat.

In the transport sector (excluding international marine bunkers, but including international aviation), energy use increased by $79 \%$ between 1970 and 2004 (STEM, 2005). Personal travel, as well as the transport of goods, is dominated by road travel. The shares of gasoline and diesel in the energy used for transport were 53\% (180 PJ) and $32 \%(110 \mathrm{PJ})$, respectively, while aviation fuel accounted for some $10 \%$ and electricity for $3 \%$ in 2003. Another $28 \mathrm{PJ}$ of diesel was reported for other sectors, primarily the agricultural, forestry, and construction sectors (Statistics Sweden, 2005a).

The pulp and paper industry is energy intensive and accounts for about half of the industrial energy use in Sweden (Statistics Sweden, 2005a). In 2000, the latest year for which data are available, the total fuel use in the pulp and paper sector was $203 \mathrm{PJ}$, of which $77 \%$ was covered by internal biomass fuels, $13 \%$ by fossil fuels and $10 \%$ by other external fuels. Additionally, $63 \mathrm{PJ}$ electricity from the grid was used in the sector (Wiberg, 2001).

The ferrous metallurgy sector used $15 \mathrm{PJ}$ of coal and $27 \mathrm{PJ}$ of coke in 2003 (Statistics Sweden, 2005a). Coke is produced in coke ovens, where coke-oven gas also is recovered. In 2003, 49PJ of coal was used for coke production. The ferrous metallurgy sector thus accounts for the main part of the Swedish use of coal. The sector also used approximately $6 \mathrm{PJ}$ of oil and $1 \mathrm{PJ}$ of natural gas.

\subsection{Swedish $\mathrm{CO}_{2}$ emissions}

The Swedish emissions of $\mathrm{CO}_{2}$ from fossil fuels and industrial processes amounted to $15.4 \mathrm{Tg} \mathrm{C}$ in 2003. An estimated net of $4.5 \mathrm{TgC}$ were taken up in carbon sinks from land use, land-use change, and forestry activities (SEPA, 2006b). Sweden's per capita $\mathrm{CO}_{2}$ emissions are among the lowest in the EU (Eurostat, 2006). Ninety-one per cent of the $\mathrm{CO}_{2}$ emissions were related to energy use, while forest land dominated as a sink (Table 3). Fuel combustion in the transport sector accounted for $35 \%$ of the $\mathrm{CO}_{2}$ emissions, while industries including energy, manufacturing, and construction accounted for $43 \%$.

\section{A scenario analysis of biomass use options}

In this section, we construct four plausible scenarios for increasing the use of biomass in Sweden by up to $400 \mathrm{PJ} /$ year, and examine how the different uses of biomass on a national scale will contribute towards reducing $\mathrm{CO}_{2}$ emission and oil use. The first scenario devotes biomass to those uses that result in the largest reductions in $\mathrm{CO}_{2}$ emissions per unit of biomass. The second scenario assigns biomass to uses that result in large reductions in oil use per
Table 3

Swedish $\mathrm{CO}_{2}$ emissions and sinks in 2003 (SEPA, 2006b)

\begin{tabular}{lrc}
\hline Source/sink & $\begin{array}{c}\text { Emission } \\
(\text { Tg C) }\end{array}$ & Per cent \\
\hline Energy & & \\
$\quad$ Fuel combustion: energy industries & 3.55 & 23.1 \\
$\quad$ Fuel combustion: manufacturing & 3.10 & 20.1 \\
and construction & & \\
$\quad$ Fuel combustion: transport & 5.36 & 34.8 \\
$\quad$ Other fuel combustion & 1.85 & 12.1 \\
$\quad$ Fugitive emissions from fuels & 0.20 & 1.3 \\
Industrial processes & & \\
$\quad$ Mineral products & 0.53 & 3.4 \\
$\quad$ Chemical industry & 0.01 & 0.1 \\
$\quad$ Metal production & 0.71 & 0.6 \\
Solvent and other product use & 0.04 & 0.2 \\
Waste incineration & 0.03 & $100 \%$ \\
Total from above sources & 15.40 & \\
Land use, land-use change, and forestry & & \\
$\quad$ Forest land & -5.06 & \\
$\quad$ Cropland & 0.98 & \\
$\quad$ Grassland & -0.64 & \\
$\quad$ Settlements & 0.21 & \\
Total from LULUCF & -4.50 & \\
\hline
\end{tabular}

unit of biomass. The third scenario seeks those uses for biomass that simultaneously reduce both $\mathrm{CO}_{2}$ emissions and oil use. The fourth scenario assigns all biomass to ethanol production to replace gasoline.

\subsection{Replacement potentials of fossil fuels}

Here we determine the potential for biomass technologies to replace conventional, fossil-fuel technologies in the scenarios. Table 4 shows the 2003 level of activity for each fossil technology and an estimate of the technical potential to replace it with different biomass technologies. In each of the four scenarios, we select the replacement options that best fulfil the objectives of the respective scenarios. The most efficient measure is first implemented to its full technical potential, then the second best measure is implemented, and so on, until $400 \mathrm{PJ}$ of additional biomass have been used.

Several factors may constrain the extent to which new technologies can be implemented in a given sector. In the heating sector, for example, not all end-use heating systems are appropriate for all buildings. District heating requires a certain heat density, and heat pumps require a suitable heat source. The fraction of detached houses with a particular type of heating system that are located in a densely populated area has been estimated by K-Konsult (2001), and these data are used here. We also assume that a pellet boiler could be installed in all houses that currently have a boiler. Mediumscale heating includes heating of multi-family houses and public and private facilities. We assume that fossil fuel and electric heating in medium-scale systems can be replaced by district heating or pellet boiler systems, with the same constraints as for small-scale heating technologies. 
Table 4

Current levels of fossil use in Sweden, and potentials to replace with biomass intensive technologies

\begin{tabular}{|c|c|c|}
\hline Fossil use & Current level of use/activity & Potential replacement ${ }^{\mathrm{a}}$ \\
\hline \multicolumn{3}{|c|}{ Small-scale heating in densely populated areas (1-3) } \\
\hline Oil boiler & 20.4 PJ oil & PB: $100 \%$, HP: $10 \%$, DH: $95 \%$ \\
\hline Gas boiler & $0.7 \mathrm{PJ}$ natural gas & PB: $95 \%$, HP: $10 \%$, DH: $95 \%$ \\
\hline Electric boiler & 19.0 PJ electricity & PB: $95 \%$, HP: $10 \%$, DH: $95 \%$ \\
\hline Resistance heaters & 18.0 PJ electricity & PB: 95\%, HP: $10 \%$, DH: $95 \%$ \\
\hline \multicolumn{3}{|c|}{ Small-scale heating in sparsely populated areas (1-3) } \\
\hline Oil boiler & 8.4 PJ oil & PB: $100 \%$, HP: $50 \%$, DH: $0 \%$ \\
\hline Electric boiler & 7.8 PJ electricity & PB: $95 \%$, HP: $50 \%$, DH: $0 \%$ \\
\hline Resistance heaters & 9.7 PJ electricity & PB: $95 \%$, HP: $50 \%$, DH: $0 \%$ \\
\hline \multicolumn{3}{|l|}{ Medium-scale heating $(1,2)$} \\
\hline Oil boiler & 20.5 PJ oil & PB: $100 \%$, DH: $80 \%$ \\
\hline Gas boiler & 3.7 PJ natural gas & PB: $95 \%$, DH: $80 \%$ \\
\hline Electric boiler & 4.7 PJ electricity & PB: $95 \%$, DH: $80 \%$ \\
\hline Resistance heaters & 9.3 PJ electricity & PB: $95 \%$, DH: $80 \%$ \\
\hline Industrial oil use $(1,4,5)$ & $54 \mathrm{PJ}$ oil & Process heat, biomass boiler: $20 \%$, space heat: PB $30 \%$, DH $25 \%$ \\
\hline District heating (6) & 11.9 PJ oil & BIG/CC CHP: $20 \%$, wood powder burner: $65 \%$ \\
\hline \multicolumn{3}{|l|}{ Electricity production (6) } \\
\hline Oil power plant & $8.7 \mathrm{PJ}$ oil & $\mathrm{BIG} / \mathrm{CC}: 50 \%$ \\
\hline Coal power plant & 6.4 PJ coal & $\mathrm{BIG} / \mathrm{CC}: 100 \%$ \\
\hline \multicolumn{3}{|l|}{ Transport (7) } \\
\hline Gasoline & $180 \mathrm{PJ}$ gasoline & Methanol: $95 \%$ \\
\hline Diesel & $138 \mathrm{PJ}_{\text {diesel }}^{\mathrm{b}}$ & DME: $100 \%$ \\
\hline Building construction (8) & 20,000 apartments, concrete frame & Wood frame: $75 \%$ \\
\hline Metallurgy (9) & 41.6 PJ coke & Charcoal: $100 \%$ \\
\hline \multicolumn{3}{|l|}{ Pulp and paper } \\
\hline Black liquor (10) & 138 GJ black liquor & BLG: $75 \%$ \\
\hline Lime kilns (4) & $6 \mathrm{PJ}$ oil & Biomass fuel: $75 \%$ \\
\hline
\end{tabular}

(1) Statistics Sweden (2004a), (2) Statistics Sweden (2004b), (3) K-Konsult (2001), (4) Wiberg (2001), (5) SEPA (2006a), (6) Statistics Sweden (2005b), (7) Statistics Sweden (2005a), (8) Boverket (2006), (9) Statistics Sweden (2006b), (10) Statistics Sweden (2004c).

${ }^{a}$ PB: pellet boiler; HP: heat pump; DH: district heating. For some categories, several possible biomass technologies are considered and they may have different potentials to replace the current use. In the case of oil boilers, for example, pellet boilers have the potential to replace $100 \%$ of oil boilers but district heating systems have the potential to replace less than $100 \%$. The implementation of one technology will limit the potential for others.

${ }^{\mathrm{b}}$ Including $28.3 \mathrm{PJ}$ delivered to other sectors than transport.

The industrial sector used $54 \mathrm{PJ}$ of fuel oil in 2003 (Statistics Sweden, 2005a), though a complete breakdown of what this oil was used for is unavailable. Statistics Sweden (2004a) estimates the use of oil for space heating in industrial premises at about $17 \mathrm{PJ}$. Information on fossil fuels used for industrial processes is limited, but potentials have been identified to replace oil used to generate process steam in e.g. the pulp and paper industry (Wiberg, 2001; Statistics Sweden, 2004a; SEPA, 2006a). Some of this oil is used as peak-load fuel, for start-ups, and as backup fuel. In total, we assume that $50 \%$ of the $54 \mathrm{PJ}$ of fuel oil used by the industrial sector can be replaced with biomass fuels: $10 \mathrm{PJ}$ of oil used for process heat and $17 \mathrm{PJ}$ of oil for heating of industrial premises. This is an uncertain assumption and further analysis will allow more precise calculations.

In the heat and power sector, oil is used mainly as a peakload fuel. We assume that $20 \%$ of the oil used in stand-alone heat production is for base-load production and can be replaced by wood boilers, and that $80 \%$ of the remaining oil for peak-load production can be replaced using wood-powder burners fed with wood pellets. For electricity production, we assume that all of the coal and $50 \%$ of the oil can be replaced by biomass-based production, partly due to load curve changes induced by reduced electric space heating.

Increased use of biomass in the construction sector is based on a near-term prognosis of the number of apartment buildings to be built in Sweden (Boverket, 2006). We assume that $75 \%$ of these multi-family dwellings would be built with wooden structural frames rather than reinforced concrete.

The technical processes currently used in the Swedish ferrous metallurgy sector do not allow a large-scale replacement of coke by charcoal. Nevertheless, biomass has been suggested as a potential future replacement for coal and coke in the iron-making industry (Gupta, 2003). As an indication of the full potential of this technology, we assume that all coke could be replaced by charcoal, acknowledging that this would require significant changes in the metallurgy industry. The uncertainty of this assumption is significant only for the $\mathrm{CO}_{2}$ reduction scenario, because using biomass in the metallurgical sector is not among the technological options selected in the other three scenarios. 


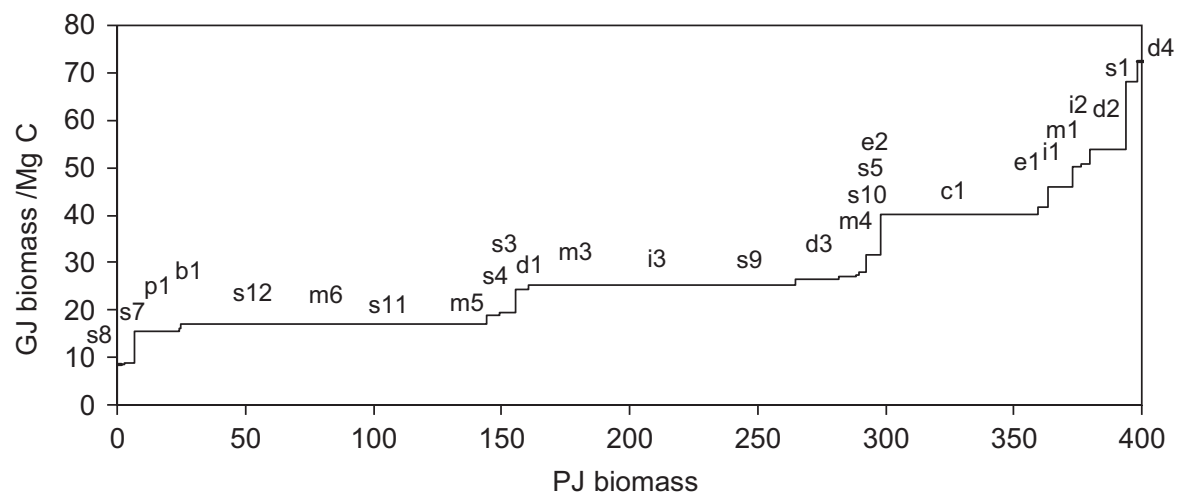

Fig. 2. Biomass cost to reduce $\mathrm{CO}_{2}$ emission (GJ biomass/Mg C) in the $\mathrm{CO}_{2}$ emission reduction scenario. The technologies are selected in order of increasing biomass cost and are assumed to be implemented in order until the available biomass resource is fully committed. The labels on the line segments refer to the technologies listed in Table 2.

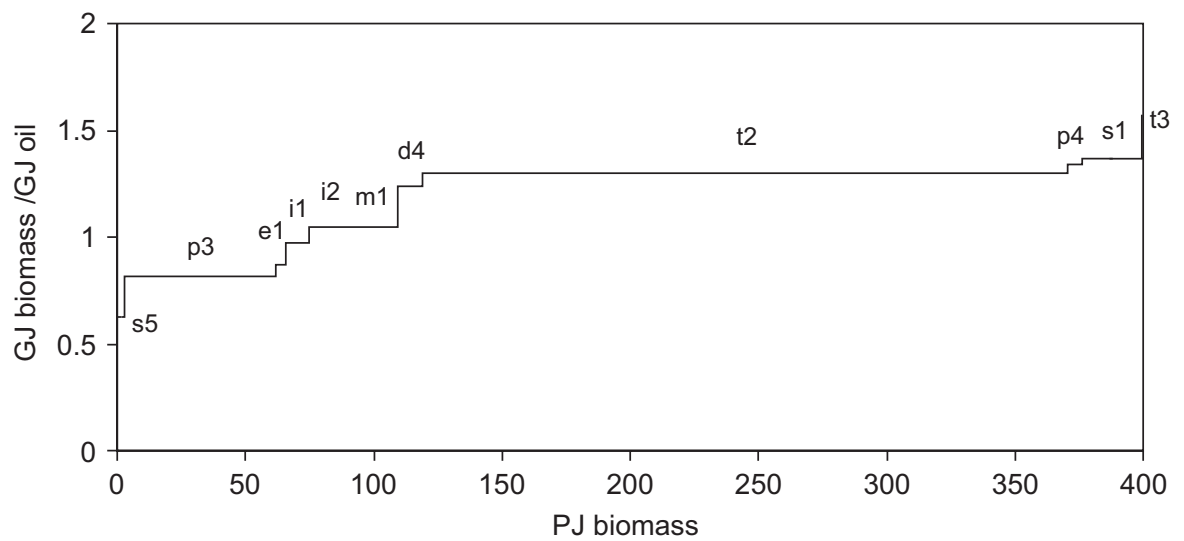

Fig. 3. Biomass cost to reduce oil use (GJ biomass/GJ oil) in the oil reduction scenario. The technologies are selected in order of increasing biomass cost and are assumed to be implemented in order until the available biomass resource is fully committed. The labels on the line segments refer to the technologies listed in Table 2 .

\section{2. $\mathrm{CO}_{2}$ emission reduction scenario}

This scenario involves selection of those technologic substitutions that require the smallest biomass use per unit of $\mathrm{CO}_{2}$ emission reduction (Fig. 2). The technologies that most efficiently use biomass to reduce $\mathrm{CO}_{2}$ emissions are the replacement of various heating technologies using electricity ("s" and " $\mathrm{m}$ " options), the construction of wood buildings (b1), and the production of electricity from black liquor (p1). Replacing electric space heating with heat pumps $(\mathrm{s} 7, \mathrm{~s} 8)$ has a lower biomass cost per unit of $\mathrm{CO}_{2}$ reduction than does replacing electric space heating with district heating $(\mathrm{s} 11, \mathrm{~s} 12)$, but the $\mathrm{CO}_{2}$ reduction per unit of replaced heat demand is higher for district heating because electricity is cogenerated. Therefore, the implementation of district heating is maximised in this scenario, despite its higher biomass cost, to optimise the overall $\mathrm{CO}_{2}$ reduction.

\subsection{Oil use reduction scenario}

This scenario devotes biomass to those uses that require the smallest biomass use per unit of oil use reduction (Fig. 3).
The replacement of oil boilers for the production of heat $(\mathrm{s} 5, \mathrm{~m} 1, \mathrm{i} 1, \mathrm{i} 2)$ and electricity (e1), and the production of methanol from black liquor (p3) are the most efficient options. The production of methanol from black liquor (p3) is more favourable than the production of transport fuels in stand-alone facilities (t2). Replacement of industrial process heat (i1) as well as space heating (i2) is also more favourable than stand-alone transport fuel production.

\subsection{Combined $\mathrm{CO}_{2}$ emission and oil use reduction scenario}

In the combined scenario, we seek to optimise the reduction of both $\mathrm{CO}_{2}$ emissions and oil use, giving equal priority to both goals. Whereas in the previous two scenarios, it is clear how to prioritise the sequence of technologic adoptions, in this case it is necessary to select a suite of options to optimise the collective effect (see Section 3.3). The options have been ranked according to a weighted biomass cost of $\mathrm{CO}_{2}$ emissions reduction and oil use reduction, where the value of each unit of $\mathrm{CO}_{2}$ emissions or oil use reduced is assigned in relation to the reduction achievable if only one goal were prioritised. The weighted 
biomass cost is calculated as

$$
c_{i}=\frac{1}{1 /\left(W_{\mathrm{CO}_{2}} \times c_{i, \mathrm{CO}_{2}}\right)+1 /\left(W_{\mathrm{oil}} \times c_{i, \mathrm{oil}}\right)},
$$

where $c_{i}$ is the weighted biomass cost of technology $i, c_{i, \mathrm{CO}_{2}}$ the biomass cost of $\mathrm{CO}_{2}$ reduction for technology $i, c_{i, \text { oil }}$ the biomass cost of oil reduction for technology $i, W_{\mathrm{CO}_{2}}$ is the maximum achievable $\mathrm{CO}_{2}$ reduction with $400 \mathrm{PJ}$ of biomass, and $W_{\text {oil }}$ the maximum achievable oil reduction with $400 \mathrm{PJ}$ of biomass (i.e. $W_{\mathrm{CO}_{2}}$ and $W_{\text {oil }}$ are the reductions achieved in the $\mathrm{CO}_{2}$ reduction and oil reduction scenarios, respectively). The unit of the weighted biomass cost is GJ of biomass.

Figs. 4 and 5 show the combined scenario with regard to the $\mathrm{CO}_{2}$ emissions and oil use reduction objectives, respectively. Both the $\mathrm{CO}_{2}$ emission and oil use reduction scenarios show that replacing electric and oil-based heating are efficient options. Also, increased use of wood in construction, BLG for electricity generation or motor fuels production, and replacing oil in stand-alone heat and power production are efficient options. Heat pumps with biomass-based electricity replacing oil boilers is the most efficient way to reduce the oil used in space heating applications, but district heating with biomass-based CHP can avoid more $\mathrm{CO}_{2}$ emissions since the co-generated electricity replaces power produced in stand-alone coalfired plants. In this scenario, district heating dominates in densely populated areas, replacing $50 \%$ of the total heat demand currently supplied by oil and electricity. Heat pumps $(20 \%)$ and pellet boilers $(30 \%)$ supply the remaining small-scale heating demand. Electric heating in multifamily houses is replaced by district heating, while fossil fuel boilers are replaced by biomass boilers $(50 \%)$ and district heating $(50 \%)$. Oil used for space heating in industry is also replaced by pellet boilers and district heating in equal amounts. A strategy that focuses on this group of options seems to be an efficient approach if both oil reduction and climate change mitigation are given equal priority. BLG for transport fuel production gives $\mathrm{CO}_{2}$ and oil use reductions, while electricity production from black liquor gives only $\mathrm{CO}_{2}$ emission reduction.

\subsection{Ethanol scenario}

The ethanol scenario uses all available, additional biomass for ethanol production to replace gasoline. About

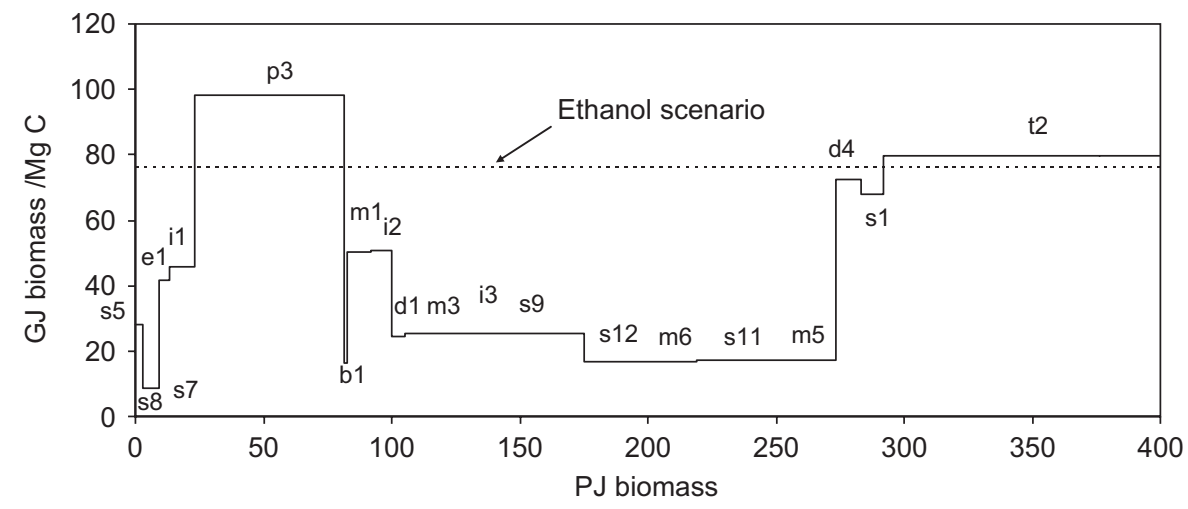

Fig. 4. Biomass cost to reduce $\mathrm{CO}_{2}$ emissions ( $\mathrm{GJ}$ biomass/Mg C) in the combined scenario, when reduction of $\mathrm{CO}_{2}$ emissions and oil use are given equal priority. The biomass cost for $\mathrm{CO}_{2}$ emission reduction in the ethanol scenario is also shown (dotted line). The labels on the line segments refer to the technologies listed in Table 2.

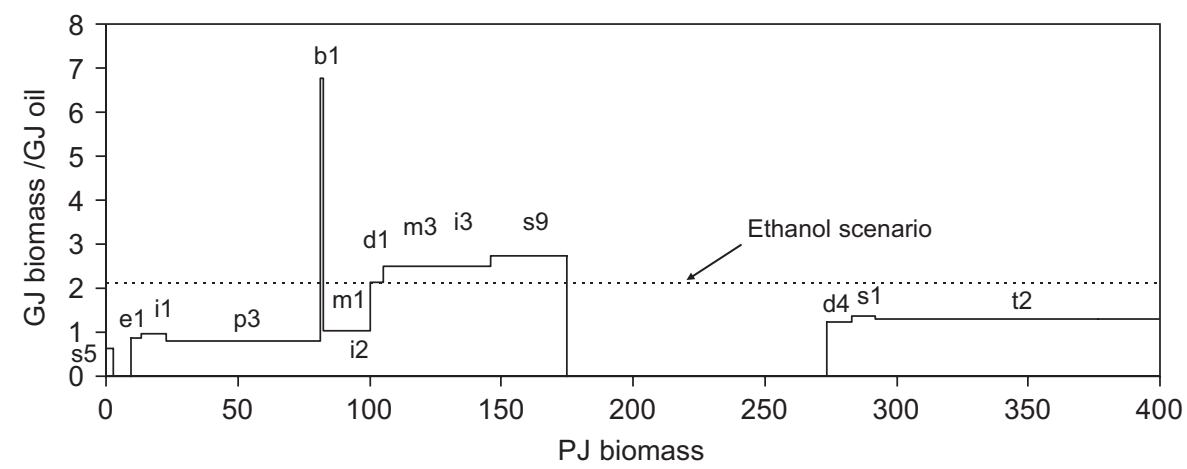

Fig. 5. Biomass cost to reduce oil use (GJ biomass/GJ oil) in the combined scenario, when reduction of $\mathrm{CO}_{2}$ emissions and oil use are given equal priority. Negative costs indicate that oil use is increased, but the magnitude of the negative mitigation costs has no clear interpretation so only positive values are shown. The biomass cost for oil use reduction in the ethanol scenario is also shown (dotted line). The labels on the line segments refer to the technologies listed in Table 2; the line segments associated with negative values can be identified by comparison with Fig. 4. 
$400 \mathrm{PJ}$ of biomass are needed to replace the present use of gasoline, so no other options are implemented in the ethanol scenario. The biomass cost of $\mathrm{CO}_{2}$ emissions reduction for the ethanol scenario is $76.1 \mathrm{GJ}$ biomass $/ \mathrm{Mg}$ $\mathrm{C}$, and this is shown as a straight, dotted line in Fig. 4. The biomass cost of oil use reduction for the ethanol scenario is $2.11 \mathrm{GJ}$ biomass/GJ oil, and this is similarly shown in Fig. 5.

\subsection{Cumulative effects of scenarios}

In each scenario, biomass is used for the application that maximises the scenario objective, until the potential of that application is fulfilled. Additional biomass is then used for the next application that best meets the objective, until that application is fulfilled, and so on. At any given amount of biomass used, the cumulative achievement is the sum of the individual reductions of $\mathrm{CO}_{2}$ emissions or oil use for all the measures implemented up to that amount of biomass use.

In Fig. 6, the cumulative contribution towards meeting the $\mathrm{CO}_{2}$ emissions and oil use reduction objectives is shown for each of the four scenarios. The cumulative $\mathrm{CO}_{2}$ mitigation when $400 \mathrm{PJ}$ biomass are prioritised for $\mathrm{CO}_{2}$ emissions reduction is about $17.4 \mathrm{Tg} \mathrm{C}$, or more than three times greater than for the ethanol scenario and the oil reduction scenario. The cumulative $\mathrm{CO}_{2}$ emission reduc- tion of the combined scenario is $12.6 \mathrm{Tg} \mathrm{C}$, or about $72 \%$ of the reduction of the $\mathrm{CO}_{2}$ mitigation scenario.

The cumulative oil use reduction with $400 \mathrm{PJ}$ of biomass prioritised for oil use reduction is about $347 \mathrm{PJ}$ oil (Fig. 6). This is more than five times the oil use reduction of the $\mathrm{CO}_{2}$ scenario (63 PJ). The combined scenario achieves $232 \mathrm{PJ}$ oil use reduction, or about $67 \%$ of that of the oil reduction scenario, and the ethanol scenario achieves a reduction of 190 PJ oil. The cumulative oil reduction curve of the combined scenario is almost equal to the oil reduction scenario up to about $100 \mathrm{PJ}$ of biomass. The combined scenario curve is above the ethanol scenario curve at all levels of biomass use.

The cumulative monetary and primary energy costs of each of the four scenarios are shown in Fig. 7. The combined scenario results in a monetary benefit of 45 million $€ /$ year, given our base case assumptions on fuel prices (US $\$ 40 / \mathrm{bbl}$ crude oil; $3.35 € / \mathrm{GJ}$ biomass). The ethanol scenario is by far the most expensive scenario, reaching a monetary cost of 1800 million $€ /$ year. The $\mathrm{CO}_{2}$ reduction scenario has a monetary benefit until about $320 \mathrm{PJ}$ of biomass have been used, but then becomes a net cost as more expensive technologies are implemented.

The expansion of district heating and heat pumps to replace less energy-efficient heating systems means that total primary energy use decreases significantly in the $\mathrm{CO}_{2}$ emission reduction scenario and in the combined scenario
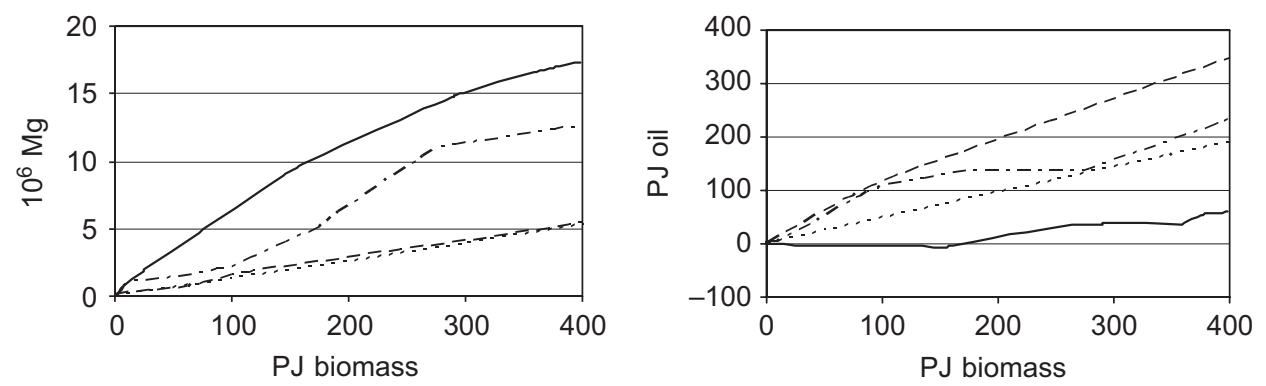

$-\mathrm{CO}_{2}----$ Oil $-\cdot-\cdot-$ Combine $\cdots \cdot \cdot$.... Ethanol

Fig. 6. Cumulative $\mathrm{CO}_{2}$ emissions reduction (left) and oil use reduction (right) for the four scenarios: maximum $\mathrm{CO}_{2}$ emission reduction ("CO${ }_{2}$ "), maximum oil use reduction ("oil"), combined $\mathrm{CO}_{2}$ and oil reduction ("combine"), and ethanol production ("ethanol").
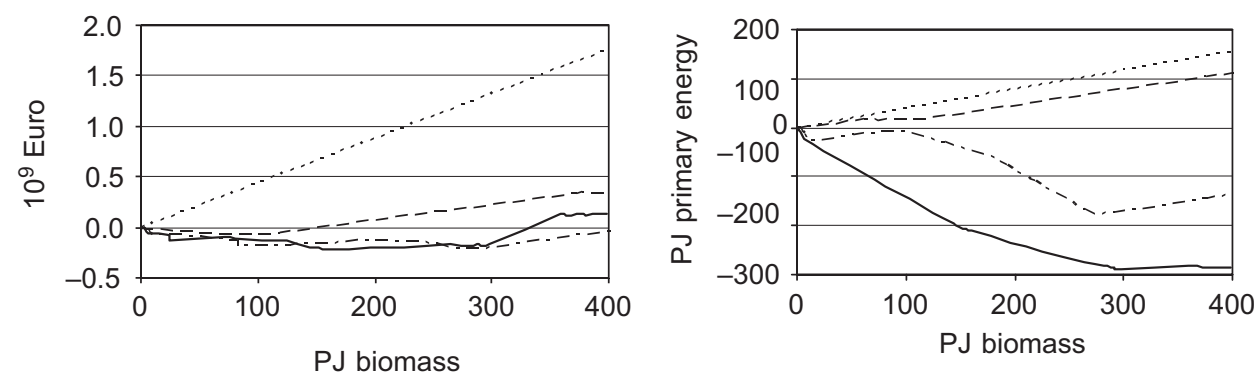

$-\mathrm{CO}_{2}---\cdot$ Oil $-\cdot-\cdot \cdot$ Combine $\cdots \cdots \cdot$. Ethanol

Fig. 7. Cumulative monetary cost (left) and primary energy cost (right) for the four scenarios: maximum $\mathrm{CO}_{2}$ emission reduction ("“ $\mathrm{CO}_{2}$ "), maximum oil use reduction ("oil"), combined $\mathrm{CO}_{2}$ and oil reduction scenario ("combine"), and ethanol production ("ethanol"). 

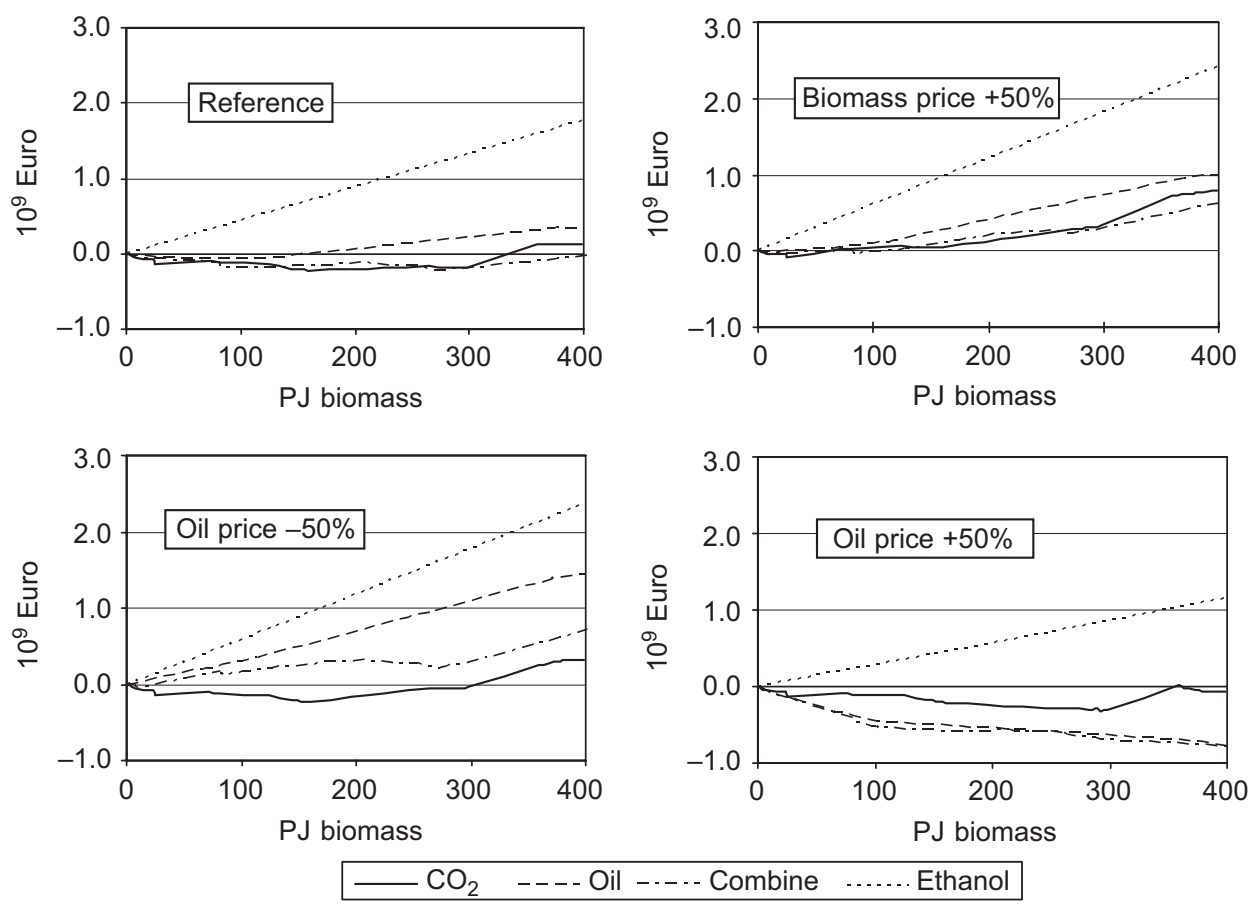

Fig. 8. Cumulative monetary costs for the four scenarios at different fuel prices. Prices are given in relation to the reference case prices (US\$40/bbl crude oil, $3.35 € / \mathrm{GJ}$ biomass).

(Fig. 7). For the $\mathrm{CO}_{2}$ scenario, the decrease is about $280 \mathrm{PJ}$ of primary energy when $400 \mathrm{PJ}$ of biomass is used. On the other hand, in the oil reduction and ethanol scenarios there is a focus on conversion of biomass to liquid fuels resulting in relatively high energy conversion losses; thus, total primary energy use increases by about 110 and $150 \mathrm{PJ}$, respectively.

The monetary cost results are very dependent on fuel prices, which have shown considerable variability and volatility. Therefore, we have recalculated all of the scenarios to illustrate the impact of different assumptions on biomass and oil prices. Cost changes for the scenarios are estimated by applying the biomass and oil price changes on the net biomass and oil use, respectively, for each scenario. Prices of refined fuels are thus assumed to change only by an amount corresponding to the feedstock cost change. Results are shown in Fig. 8. All scenarios are equally sensitive to changes in the biomass price, since all scenarios use the same amount of biomass. With the biomass price $50 \%$ higher than in the reference case, all scenarios have cumulative costs. On the other hand, the oil reduction scenario and the combined scenario are more sensitive to changes in the oil price than is the $\mathrm{CO}_{2}$ scenario. At an oil price $50 \%$ lower than that in the reference case, the cumulative cost of the $\mathrm{CO}_{2}$ scenario is lower than that for the other scenarios. At oil prices $50 \%$ higher than those in the reference scenarios, the oil reduction and combined scenarios have cumulative benefits, while the monetary cost for the $\mathrm{CO}_{2}$ scenario is close to zero. The cumulative cost for the ethanol scenario is higher than that for all of the other scenarios and remains positive for all of the evaluated price levels.

\section{Discussion}

\subsection{Trade-offs between objectives}

Increased use of biomass provides an important potential for reducing $\mathrm{CO}_{2}$ emissions and oil use. There are, however, a variety of technological options for using biomass and these options vary considerably in cost and in the extent to which they address these issues. Through development and analysis of four scenarios, we illustrate the trade-offs inherent in trying to use $400 \mathrm{PJ}$ of additional biomass to simultaneously reduce $\mathrm{CO}_{2}$ emissions and oil use. Optimising biomass use for $\mathrm{CO}_{2}$ emissions reduction leads to significantly greater reductions in $\mathrm{CO}_{2}$ emissions than if biomass use is optimised for reduction in oil use. Using $400 \mathrm{PJ}$ of biomass, $\mathrm{CO}_{2}$ emissions could be reduced by 17.4 and $5.4 \mathrm{Tg} \mathrm{C}$ in these two scenarios, respectively. On the other hand, the reduction of oil use is much larger in the oil reduction scenario, $347 \mathrm{PJ}$ of oil compared with $63 \mathrm{PJ}$ in the $\mathrm{CO}_{2}$ emission scenario. The $\mathrm{CO}_{2}$ emission reduction scenario has a monetary cost of 130 million $€ /$ year, while the oil reduction scenario costs 330 million $€ /$ year. These costs are, however, quite sensitive to changes in the price of oil and biofuels.

In the combined scenario that equally prioritises biomass uses to reduce both $\mathrm{CO}_{2}$ emissions and oil use, $400 \mathrm{PJ} /$ year of biomass results in a total reduction of $12.6 \mathrm{TgC} / \mathrm{year}$ emissions and $232 \mathrm{PJ} /$ year oil use. The $\mathrm{CO}_{2}$ emissions and oil use reductions in this scenario are $72 \%$ and $67 \%$, respectively, of the reductions achieved in the scenarios with single objectives. This combined scenario would give a 
monetary benefit of 45 million $€ /$ year, i.e. cost savings. The cumulative monetary cost curves for the combined and $\mathrm{CO}_{2}$ scenarios are very similar until about $300 \mathrm{PJ}$ of biomass have been used. After $300 \mathrm{PJ}$, the technologies used in the $\mathrm{CO}_{2}$ scenario become more expensive than those in the combined scenario; so the total monetary cost for using $400 \mathrm{PJ}$ of biomass is lower in the combined scenario than in the $\mathrm{CO}_{2}$ scenario.

The ethanol scenario reduced $\mathrm{CO}_{2}$ emissions by only $5.3 \mathrm{Tg} /$ year $\mathrm{C}$, or $30 \%$ of the reduction of the scenario aimed specifically at reducing $\mathrm{CO}_{2}$ emissions. Oil use reduction in the ethanol scenario was $190 \mathrm{PJ} /$ year, or $55 \%$ of the maximum possible. The monetary cost for this scenario was significantly more expensive than the other options, at 1800 million $€$ /year.

Given the options and assumptions considered in this study, at least two main technological options can be used to balance between the oil and $\mathrm{CO}_{2}$ objectives of energy policy: (1) district heating vs. heat pumps or pellet boilers and (2) transport fuel or electricity production from BLG. District heating seems to be the best heating option if $\mathrm{CO}_{2}$ mitigation is the highest priority, but it only reduces oil use when oil boilers are replaced. BLG seems to be an efficient technology that can produce either electricity or transport fuel, depending on the priorities.

\subsection{Uncertainties}

The results of this study, while robust overall, are subject to several uncertainties which are here identified and discussed. Our objective has not been to provide exact predictions or prescriptions for the future, but rather to show a broad picture of possible alternatives if the use of Swedish biomass is increased by up to double the current use. We have used general data collected from a number of sources, but the actual costs and efficiency of reducing $\mathrm{CO}_{2}$ emissions and oil use for a particular technology may vary with local circumstances. We focus on technologies that are available today or that are judged to become available in the near future. For technologies that are not yet commercially available, costs and performance are based on estimates with larger uncertainty than for commercial technologies.

The level of detail in the current energy-use data is different in different sectors. The industrial sector uses a large share of the oil used in Sweden, though the energy use in this sector is diverse and the available data are sparse. A more detailed study of fossil fuel replacement options in this sector would reduce uncertainties on $\mathrm{CO}_{2}$ emissions and oil use reduction potentials. Some options, for example using charcoal to replace metallurgical coke, would require substantial research and development to implement on a large scale; thus, we include these options to quantify potentials. Variation in the price of biomass has a large impact on the net cost of the different scenarios, but does not change the cost relation between the scenarios. Variations in the oil price, however, will change the monetary cost difference between the various scenarios and hence the order ranking of the scenario costs. The inclusion of taxes on carbon emission or oil use would reduce the monetary mitigation cost of the avoided emission or oil use.

We have assumed that marginal electricity production is based on coal-fired plants, which are typically located outside of Sweden. Hence, the $\mathrm{CO}_{2}$ emission reduction due to decreased use or increased production of electricity in Sweden will likely occur abroad, although typically within the EU bubble for greenhouse gas emissions. Natural gasfired power plants, which have significantly lower $\mathrm{CO}_{2}$ emission than coal-fired plants, might be an option for future marginal electricity production. The marginal fossil fuel that is replaced by an increased use of biomass will significantly affect the resulting decrease in carbon emissions, and further analysis could determine how this factor would influence the results of this study.

Our analysis incorporates structural changes in the Swedish energy system. For example, electric space heating is assumed to be replaced by district heating or heat pumps. Such structural changes will reduce primary energy use and monetary cost independent of the fuel used to supply district heat or electricity production. In our scenarios, we have not distinguished between the effects of such structural changes and the increased use of biofuels.

\subsection{Sweden in an international context}

We have focused on using Swedish biomass to meet needs within Sweden. However, from a larger system perspective, it might be possible to further reduce global $\mathrm{CO}_{2}$ emissions or oil use by using Swedish biomass in other countries. By exporting biomass to be used in applications that result in high $\mathrm{CO}_{2}$ emission or oil use reductions per unit of biomass, the total impact of the available supply of biomass could be increased. For example, substituting wood construction material in place of concrete has a high $\mathrm{CO}_{2}$ emission reduction per unit of biomass, and constructing Swedish buildings with wood instead of concrete would affect a reduction in Swedish emissions. However, the total number of new buildings built per year in Sweden is small in relation to the total quantities of biomass potentially available. If the analysis is geographically limited to Sweden, the additional biomass would then be used for other uses with lower efficiency of emission reduction. However, if additional biomass is processed and exported in the form of prefabricated houses to be used instead of non-wood houses in other countries, the higher emission reduction per unit of biomass can be gained by a larger share of the biomass, thus resulting in a greater overall emission reduction globally.

A similar potential exists for using biomass to substitute coal for electricity production. The export of Swedish biomass to replace coal used in other countries might reduce total emissions more than if all the biomass were used in Sweden. Similarly, Swedish biomass exports could be used to reduce oil use in other countries. The trade-offs 
involved in reducing global $\mathrm{CO}_{2}$ emissions and oil use by exporting Swedish biomass, and the global effects of the development and implementation of a domestic biomass strategy for Sweden, are to be further analysed.

\subsection{Learning, technology pull and lock-in}

Our results suggest that, from the perspective of reducing $\mathrm{CO}_{2}$ emission and oil use, it is efficient to use biomass in innovative technologies for electricity and heat production (heat pumps, pellet boilers, and $\mathrm{BIG} / \mathrm{CC}$ ), methanol production from BLG, and wood building construction. The implementation of such technologies could result in monetary cost savings (see Section 7.1) in addition to reductions in $\mathrm{CO}_{2}$ emission and oil use. However, it is often difficult to implement innovative technologies for several reasons. They are usually capital intensive, and financial support may be required for the initial installations to make the technologies competitive in the long run. Quite often experience curves are used to estimate "learning investments," i.e. cumulative costs for supporting new technologies so that these new technologies are competitive with the least-cost option (Neij et al., 2003). However, experience curves are not very useful for decision support except for an initial scanning. Technology learning is crucial but very uncertain to estimate. Therefore, we have based our analysis on current technology performance based on the state-of-the-art, or for technologies that could be commercialised in the short term.

Furthermore, the innovation and diffusion of innovative technologies is difficult not only because they are associated with risks and uncertainties, but also due to the path dependency of the existing innovation system. Introduction of innovative technologies requires new knowledge, actor networks, and financial resources, etc. The feedback process from markets creates technical improvements in existing technologies and tends to create "lock-in" and "lock-out" phenomenon. Arthur (1989) has argued that it is not because a particular technology is efficient that it is adopted, but rather because it is adopted that it will become efficient. Thus, technologies having a small short-term advantage may lock-in the technical basis of a society to technological choices that may have low long-term advantages. Other technologies are consequently locked-out. Technological change can go in multiple directions, but once change is initiated in a particular direction, it becomes increasingly difficult to change its course (Roehrl and Riahi, 2000). Hence, research, development, and demonstration efforts as well as investment decisions are critical in determining which long-term technological options may be opened, or which ones may be foreclosed.

For example, the use of ethanol instead of gasoline requires relatively small changes to vehicles and the fuel distribution system, so it is relatively easy to adapt to the existing system. Thus, an increased use of ethanol might strengthen the lock-in situation of existing technologies, making it more difficult to develop and diffuse radical changes that better fulfil the societal objectives. In some cases, it is difficult to introduce an innovative technology even if it is less expensive than the existing technology. An example of this is the slow diffusion of multi-storey wooden building construction (Gustavsson et al., 2006a).

\section{Conclusions}

In this study, we have analysed ways to increase the use of biomass in Sweden to reduce $\mathrm{CO}_{2}$ emissions and oil use. We have developed a methodological approach to better understand efficient ways to use a potentially important resource-biomass - given the multiple objectives of energy policy. We based this analysis on techno-economic data on using biomass to produce electricity, heat, liquid fuels, iron, and construction materials. The potential contribution of each biomass application is a function of the efficiency of reducing $\mathrm{CO}_{2}$ emissions and/or oil use (per unit of biomass), and of the extent of each application within the Swedish economy. We prioritised each option for using biomass within four scenarios, each scenario with a specific goal: maximise $\mathrm{CO}_{2}$ emissions reduction, maximise oil use reduction, simultaneously reduce both $\mathrm{CO}_{2}$ emissions and oil use, and produce ethanol for use as a liquid transport fuel.

Our results suggest that a biomass use strategy that simultaneously fulfils two important objectives of Swedish energy policy, namely, $\mathrm{CO}_{2}$ emission reduction and oil use reduction, is achievable. There would be, of course, tradeoffs when multiple objectives are pursued. The strategic use of $400 \mathrm{PJ} /$ year of additional biomass can reduce $\mathrm{CO}_{2}$ emissions by $12.6 \mathrm{Tg} \mathrm{C} /$ year and oil use by $230 \mathrm{PJ} /$ year. Strategies aimed at fulfilling only one of those objectives can achieve greater results in terms of that particular objective, but at the cost of a significantly lower effectiveness at fulfilling the other objective. A strategy of prioritising ethanol production fulfils both objectives less effectively, and at a much higher monetary cost.

The results of this analysis are based on general technological and economic data and are subject to considerable uncertainty in the details. Uncertainty applies both in terms of case-by-case variability of the effectiveness of $\mathrm{CO}_{2}$ emission and oil use reductions for each biomass application, as well as in terms of the temporal dynamics of the introduction of biomass to substitute for fossil-fuel uses. A widening of the geographic scope of the analysis, from within Sweden to a regional or global perspective, could show an increase in the potential for Swedish biomass to reduce total $\mathrm{CO}_{2}$ emission and oil use. Nevertheless, barriers exist that could hinder the large-scale diffusion of new or established biomass uses, thus focused efforts may be required to achieve in practice the potential benefits pointed to in this study. The scenarios and numerical analyses in this study could be refined to better characterise the detailed objectives of reducing $\mathrm{CO}_{2}$ emissions and oil use; nevertheless, the overall results appear to be robust. 


\section{Acknowledgements}

We thank the Swedish Energy Agency for supporting this study and an anonymous reviewer for useful comments.

\section{Appendix}

Data for the evaluation of biomass and fossil options are shown in Tables A1-A5.

Table A1

Efficiencies of electricity and heat production

$\eta_{\mathrm{el}} \quad \eta_{\text {heat }}{ }^{\mathrm{a}} \quad$ Electricity use

(\% of output)

Fossil systems

Small-scale oil boiler (1)

Small-scale gas boiler (1)

Resistance heat (2)

Electric boiler (2)

Medium-scale oil boiler (3)

Medium-scale gas boiler (1)

Industrial oil boiler (4)

Heat plant oil (1)

District heat-gas CHP (1)

District heat coal CHP (1)

Power plant oil (1)

Power plant coal (1)

$\begin{array}{lll}- & 0.98 & 2 \\ - & 1.00 & 1 \\ - & 0.97 & - \\ - & 0.95 & - \\ - & 0.90 & 0.4 \\ - & 0.90 & 2 \\ - & 0.87 & - \\ - & 0.91 & - \\ 0.45 & 0.45 & - \\ 0.32 & 0.54 & - \\ 0.42 & - & - \\ 0.42 & - & - \\ & & \\ - & 0.85 & 1.5 \\ - & 3.27 & - \\ 0.43 & 0.43 & - \\ - & 0.85 & 0.5 \\ - & 0.85 & 0.4 \\ - & 0.87 & 5 \\ 0.47 & - & -\end{array}$

Biomass systems

Small-scale pellet boiler (1)

Heat pump (2)

District heat-BIG/CC CHP (2)

Medium-scale wood boiler (3)

Industrial wood boiler $(1,4)$

Peak load plant-wood powder (5)

$\mathrm{BIG} / \mathrm{CC}$ power (2)

西

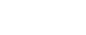

(2)

(1) UBA (2006), (2) Gustavsson and Karlsson (2002), (3) STEM (2002b), (4) Ådahl (2004), (5) Harvey (2006).

${ }^{\mathrm{a}}$ For heat plants and CHP plants, $\eta_{\text {heat }}$ refers to heat delivered to the grid. Additionally, distribution losses of $14 \%$ are accounted for in the calculations.

Table A2

Cost data on electricity and heat production

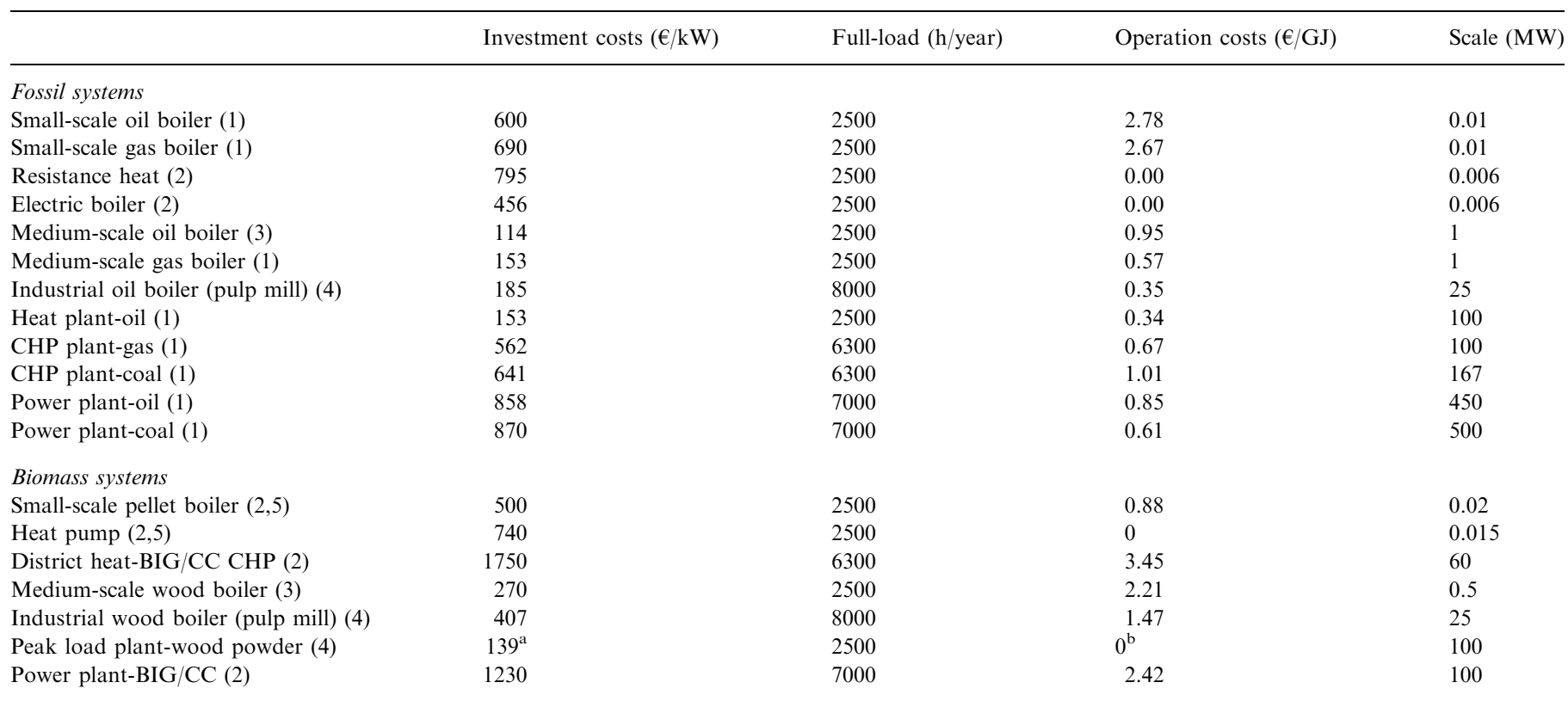

(1) UBA (2006), (2) Gustavsson and Karlsson (2002), (3) STEM (2002b), (4) Harvey (2006), (5) Gustavsson and Joelsson (2007).

${ }^{\text {a }}$ Retrofitting cost from a fossil system to a biomass system.

${ }^{\mathrm{b}} \mathrm{We}$ assume the same operation and maintenance cost for fossil and biomass systems, as no data were available. 
Table A3

Efficiencies and cost data of biofuel production

\begin{tabular}{|c|c|c|c|c|c|c|}
\hline Fuel & $\eta_{\text {fuel }}$ & $\begin{array}{l}\text { Electricity use } \\
\left(\mathrm{GJ}_{\mathrm{el}} / \mathrm{GJ}_{\text {fuel }}\right)\end{array}$ & $\begin{array}{l}\text { End-use efficiency } \\
\left(\mathrm{km}_{-} \text {bio } / \mathrm{km}_{-} \text {fossil }\right)\end{array}$ & $\begin{array}{l}\text { Investment costs } \\
(€ / \mathrm{kW})\end{array}$ & Full load (h/year) & $\begin{array}{l}\text { Operation costs } \\
(€ / G J)\end{array}$ \\
\hline Ethanol (1) & 0.38 & 0.05 & $1.16^{\mathrm{a}}$ & 2350 & 8000 & 5.23 \\
\hline Methanol (1) & 0.62 & -0.05 & $1.12^{\mathrm{a}}$ & 1150 & 8000 & 1.60 \\
\hline DME (2) & 0.63 & -0.07 & $1.00^{\mathrm{b}}$ & 1465 & 8000 & 4.34 \\
\hline FT-diesel (1) & 0.48 & 0.03 & $1.00^{\mathrm{b}}$ & 1875 & 8000 & 2.87 \\
\hline
\end{tabular}

(1) Hamelinck and Faaij (2006), (2) Bio-DME Consortium (2002).

${ }^{a}$ Fossil fuel refers to gasoline. The data represent intermediate values from the literature.

${ }^{\mathrm{b}}$ Fossil fuel refers to diesel.

Table A4

Primary energy use (GJ) for production of materials for wood and concrete versions of wood- and concrete-framed versions of multi-storey apartment building, broken down by end-use energy carrier

\begin{tabular}{|c|c|c|c|c|}
\hline & Final-use & Conversion/distribution & Fuel cycle & Total \\
\hline Wood-frame & & & & 2730 \\
\hline Electricity & 320 & 498 & 98 & 920 \\
\hline Coal & 367 & 0 & 44 & 410 \\
\hline Oil & 831 & 0 & 25 & 860 \\
\hline Natural gas & 61 & 0 & 1 & 60 \\
\hline Biofuel & 490 & 0 & 0 & 490 \\
\hline Concrete-frame & & & & 3410 \\
\hline Electricity & 366 & 567 & 112 & 1050 \\
\hline Coal & 729 & 0 & 87 & 820 \\
\hline Oil & 1019 & 0 & 31 & 1050 \\
\hline Natural gas & 96 & 0 & 1 & 100 \\
\hline Biofuel & 398 & 0 & 0 & 400 \\
\hline
\end{tabular}

Gustavsson et al. (2006b).

Table A5

Key parameters for model mills with black liquor gasification and the reference mill

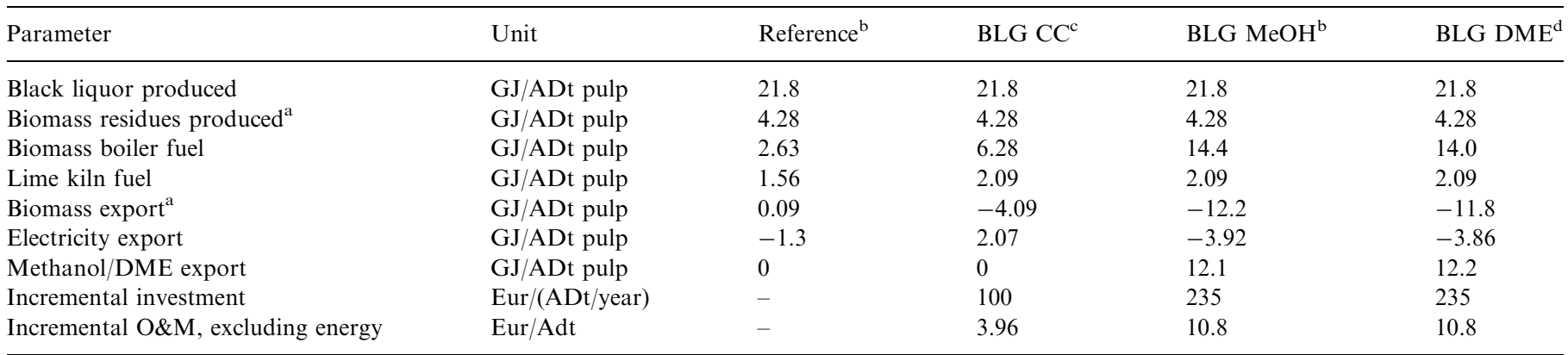

Values are given per air-dry tonne (ADt) of pulp produced

${ }^{\mathrm{a}}$ Including tall oil.

${ }^{\mathrm{b}}$ Berglin et al. (2003).

${ }^{\mathrm{c}}$ Berglin et al. (2003), cost data from STFI (2003).

${ }^{\mathrm{d}}$ Estimated for DME from Berglin et al. (2003).

\section{References}

Ådahl, A., 2004. Process industry energy projects in a climate change conscious economy. Ph.D. Thesis, Department of Chemical Engineering and Environmental Science, Chalmers University of Technology, Gothenburg, Sweden.

Ahlvik, P., Brandberg, А., 2001. Well-to-wheel efficiency for alternative fuels from natural gas or biomass. Report No. 2001:85, Swedish National Road Administration, Borlänge, Sweden.
Antal, M.J., Croiset, E., Dfai, X., De Almeida, C., Mok, W.S.-L., Norberg, N., Richard, J.-R., Al Majthoub, M., 1996. High-yield biomass charcoal. Energy and Fuels 10, 652-658.

Arthur, W.B., 1989. Competing technologies, increasing returns and lockin by historical events. The Economic Journal 99, 116-131.

Berg, S., Lindholm, E.-L., 2005. Energy use and environmental impacts of forest operations in Sweden. Journal of Cleaner Production 13, 33-42.

Berglin, N., Lindblom, M., Ekbom, T., 2003. Preliminary economics of black liquor gasification with motor fuels production. In: 
Colloquium on Black Liquor Combustion and Gasification, Park City, UT, USA.

Berndes, G., Hoogwijk, M., van den Broek, R., 2003. The contribution of biomass in the future global energy supply: a review of 17 studies. Biomass and Bioenergy 25 (1), 1-28.

Bio-DME Consortium, 2002. The Bio-DME Project Phase 1. Report to Swedish National Energy Administration-Non-Confidential Version, April.

Boverket, 2006. Byggprognos för 2005-2007. Web-accessible at $\langle$ www.boverket.se/ $>$.

Börjesson, P., 1996. Energy analysis of biomass production and transportation. Biomass and Bioenergy 11 (4), 305-318.

Börjesson, P., Gustavsson, L., 2000. Greenhouse gas balances in building construction: wood versus concrete from lifecycle and forest land-use perspectives. Energy Policy 28 (9), 575-588.

Börjesson, P., Gustavsson, L., Christersson, L., Linder, S., 1997. Future production and utilisation of biomass in Sweden: potentials and $\mathrm{CO}_{2}$ mitigation. Biomass and Bioenergy 13 (6), 399-412.

Commission on Oil Independence, 2006. Making Sweden an Oil-Free Society. Swedish Government Offices, Stockholm Web-accessible at $\langle$ http://www.sweden.gov.se/sb/d/2031/a/67096〉.

Danko, J., Lösönen, P., 2006. Combined Heat and Power (CHP) Electricity Generation in the EU-25 in 2002 Totalled 299.2 TWh, $9.9 \%$ of Total Gross Electricity Generation. Eurostat, Luxembourg.

Diemer, P., Killich, H.-J., Knop, K., Lüngen, H.B., Reinke, M., Schmöle, P., 2004. Potentials for utilization of coke oven gas in integrated iron and steel works. In: Second International Meeting on Ironmaking/First International Symposium on Iron Ore, Espírito Santo, Brazil.

EC, 1997. Energy for the Future: Renewable Sources of Energy, White Paper for a Community Strategy and Action Plan (COM (97) 599 final). European Commission, Brussels.

EC, 2000. Green Paper-Towards a European Strategy for the Security of Energy Supply (COM(2000) 769 Final). European Commission, Brussels.

EC, 2005. Communication from the Commission: Biomass Action Plan (COM (2005) 628 Final). European Commission, Brussels.

Eikeland, I.J., Monsen, B.E., Modahl, I.S., 2001. Reducing $\mathrm{CO}_{2}$ emissions in Norwegian ferroalloy production. In: Conference of Metallurgists 2001, Toronto, Canada.

EU, 2003. Directive 2003/30/EC of the European Parliament and of the Council of 8 May 2003 on the promotion of the use of biofuels or other renewable fuels for transport, IJ L 176, 15.7.2003, European Union, pp. $42-46$.

Eurostat, 2005. Energy-Yearly Statistics 2003. Product Code: KS-CN-05001. Eurostat, Luxembourg Web-accessible at:〈http://epp.eurostat. cec.eu.int $/>$.

Eurostat, 2006. $\mathrm{CO}_{2}$ emissions per capita in the EU and in developing countries. Web-accessible at 〈http://epp.eurostat.ec.europa.eu/ $\rangle$.

FAO, 1964. Use of charcoal in blast furnace operations. Unasylva 18 (1).

Fischer, G., Schrattenholzer, L., 2001. Global bioenergy potentials through 2050. Biomass and Bioenergy 20 (3), 151-159.

Gupta, R.C., 2003. Woodchar as a sustainable reductant for ironmaking in the 21st century. Mineral Processing and Extractive Metallurgical Review 24, 203-231.

Gustavsson, L., Joelsson, A., 2007. Energy conservation and conversion of electrical heating systems in detached houses. Energy and Buildings 39, 717-726.

Gustavsson, L., Karlsson, А., 2002. A system perspective on the heating of detached houses. Energy Policy 30, 553-574.

Gustavsson, L., Karlsson, А., 2006. $\mathrm{CO}_{2}$ mitigation: on methods and parameters for comparison of fossil-fuel and biofuel systems. Mitigation and Adaptation Strategies for Global Change 11 (5-6), 935-959.

Gustavsson, L., Sathre, R., 2006. Variability in energy and carbon dioxide balances of wood and concrete building materials. Building and Environment 41, 940-951.

Gustavsson, L., Madlener, R., Hoen, H.-F., Jungmeier, G., Karjalainen, T., Klöhn, S., Mahapatra, K., Pohjola, J., Solberg, B., Spelter, H., 2006a. The role of wood material for greenhouse gas mitigation. Mitigation and Adaptation Strategies for Global Change 11 (5-6), 1097-1127.

Gustavsson, L., Pingoud, K., Sathre, R., 2006b. Carbon dioxide balance of wood substitution: comparing concrete- and wood-framed buildings. Mitigation and Adaptation Strategies for Global Change 11 (3), 667-691.

Hagström, P., 2006. Biomass potential for heat, electricity and vehicle fuel in Sweden. Ph.D. Thesis, Department of Bioenergy, Swedish University of Agricultural Sciences, Uppsala.

Hamelinck, C.N., Faaij, A.P.C., 2006. Outlook for advanced biofuels. Energy Policy 34 (17), 3268-3283.

Harvey, S., 2006. Personal Communication. Chalmers University of Technology, Gothenburg, Sweden, 29 September.

Hobbs, B.F., Meier, P., 2003. Energy Decisions and the Environment-A Guide to the Use of Multicriteria Methods. Kluwer Academic Publishers, Boston.

IEA, 2005. Key World Energy Statistics. International Energy Agency, Paris Web accessible at $\langle$ http://www.iea.org/ $>$.

IEA, 2006. Energy Statistics and Energy Balances. International Energy Agency, Paris Web-accessible at $\langle$ http://www.iea.org/ $\rangle$.

Jernkontoret, 2006. Swedish crude steel production by quality and process. Web-accessible at $\langle w w w . j e r n k o n t o r e t . s e /\rangle$.

JRC, 2005. Well-to-wheels analysis of future automotive fuels and powertrains in the European context, Version 2a, December.

K-Konsult, 2001. Typhuskatalog. K-Konsult Energi Stockholm AB, Stockholm, Sweden.

MacLean, H.L., Lave, L.B., 2000. Environmental implications of alternative-fueled automobiles: air quality and greenhouse gas tradeoffs. Environmental Science and Technology 34, 225-231.

MacLean, H.L., Lave, L.B., 2003. Evaluating automobile fuel/propulsion system technologies. Progress in Energy and Combustion Science 29, $1-69$.

Möllersten, K., 2002. Opportunities for $\mathrm{CO}_{2}$ reductions and $\mathrm{CO}_{2}$-lean energy systems in pulp and paper mills. Ph.D. Thesis, Chemical Engineering and Technology, Royal Institute of Technology, Stockholm, Sweden.

Neij, L., Andersen, P.D., Durstewitz, M., Helby, P., Hopper_Kilpper, M., Morthorst, P.E., 2003. Experience curves: a tool for energy policy assessment (EXTOOL).

Näslund, L., Gustavsson, L., 2007. Biofuels from stumps and small round wood - costs and $\mathrm{CO}_{2}$ benefits. Manuscript.

Persson, S., 1998. Wälludden trähus i fem våningar: erfarenheter och lärdomar (Wälludden wooden building with five stories: experiences and knowledge acquired). Report TVBK-3032, Department of Structural Engineering, Lund Institute of Technology (in Swedish).

Roehrl, R.A., Riahi, K., 2000. Technology dynamics and greenhouse gas emissions mitigation: a cost assessment. Technological Forecasting and Social Changes 63 (2-3), 231-261.

Schlamadinger, B., Apps, M., Bohlin, F., Gustavsson, L., Jungmeier, G., Marland, G., Pingoud, K., Savolainen, I., 1997. Towards a standard methodology for greenhouse gas balances of bioenergy systems in comparison with fossil energy systems. Biomass and Bioenergy 13 (6), 359-375.

Schlamadinger, B., Edwards, R., Byrne, K.A., Cowie, A., Faaij, A., Green, C., Fijan-Parlov, S., Gustavsson, L., Hatton, T., Heding1, N., Kwant, K., Pingoud, K., Ringer, M., Robertson, K., Solberg, B., Soimakallio, S., Woess-Gallasch, S., 2005. Optimizing the greenhouse gas benefits of bioenergy systems. Presented at 14th European Biomass Conference, 17-21 October 2005, Paris.

SEPA, 2006a. Bedömning av möjligheterna att minska utsläppen av fossil koldioxid från de industrisektorer som ingår i systemet för handel med utsläppsrätter. Dnr 503-677-05 Hk. Swedish Environmental Protection Agency, Stockholm, Sweden. Web-accessible at <http:// www.naturvardsverket.se/dokument/hallbar/klimat/utslappshandel/ utslappshand/pdf/bedomning_nv.pdf $>$ (in Swedish). 
SEPA, 2006b. Emission Data Reported by Sweden under the Climate Convention, 2004. Swedish Environmental Protection Agency, Stockholm, Sweden Web-accessible at $\langle$ http://www.internat.naturvardsverket.se/ $\rangle$.

Skogsstyrelsen, 2006. Korta fakta om skog och skogsmark. Webaccessible at 〈http://www.svo.se/minskog/templates/svo_sverige. asp?id $=1984>$.

Statistics Sweden, 2004a. Energistatistik för småhus, flerbostadshus och lokaler 2003. Report No.: EN16SM0404. Statistics Sweden, Örebro, Sweden.

Statistics Sweden, 2004b. Energistatistik för småhus 2003. Report No.: EN16SM0403. Statistics Sweden, Örebro, Sweden.

Statistics Sweden, 2004c. Bränslen. Leveranser och förbrukning av bränsle fjärde kvartalet 2003. Report No. EN31SM0401. Statistics Sweden, Örebro, Sweden.

Statistics Sweden, 2005a. Årliga energibalanser 2002-2003, Report No. EN20SM0501, Statistics Sweden, Örebro, Sweden.

Statistics Sweden, 2005b. El-, gas- och fjärrvärmeförsörjningen 2003. Report No. EN11SM0501. Statistics Sweden, Örebro, Sweden.

Statistics Sweden, 2006a. Building price index with deduction for allowances and CPI. Web-accessible at $\langle$ http://www.scb.se $\rangle$.

Statistics Sweden, 2006b. Energy use in manufacturing industry, 2004. Web accessible at $\langle$ www.scb.se/ $/$.

STEM, 2002a. Marginal elproduktion och $\mathrm{CO}_{2}$-utsläpp i Sverige. Swedish Energy Agency, Eskilstuna, Sweden.

STEM, 2002b. Biobränsle från skogen-en studie av miljökonsekvenser och ekonomi för olika användningar. Swedish Energy Agency, Eskilstuna, Sweden.
STEM, 2003. Ekonomiska styrmedel inom energiområdet. Web-accessible at $\langle$ http://www.stem.se/ $\rangle$.

STEM, 2004. Energiläget i siffror 2004. Report ET2004:18. Swedish Energy Agency, Eskilstuna, Sweden. Web-accessible at 〈http:// www.stem.se/ $>$.

STEM, 2005. Energy in Sweden 2005. Report ET2005:25. Swedish Energy Agency, Eskilstuna, Sweden. Web-accessible at $\langle$ http://www.stem.se $/\rangle$.

STEM, 2006. Prisblad för biobränslen, torv m.m. Nr 3/2006. Swedish Energy Agency, Eskilstuna, Sweden Web-accessible at $\langle$ http://www.stem.se $/\rangle$.

STFI, 2003. Ecocyclic Pulp Mill-KAM Final Report. KAM Report A100. Swedish Pulp and Paper Research Institute, Stockholm.

Swedish Government, 2007. Energy Policy. Web-accessed at 〈http:// www.sweden.gov.se/sb/d/5745/a/19594 > on 5 March 2007.

UBA, 2006. Prozessorientierte Basisdaten für UmweltmanagementInstrumente (ProBas). Web-accessible at $\langle$ http://www.probas.umweltbundesamt.de/php/index.php $\rangle$ (in German).

VärmeForsk, Undated. Inbjudan till Värmeforsks och Stiftelsen Lantbruksforsknings gemensamma forskningsprogram åren 2006-2009: Grödor från åker till energiproduktion-salix, halm, spannmål, rörflen, och hampa. Web-accessible at <www.varmeforsk.se/administration/mojligafiler/Program_agrara_slut.pdf $\rangle$.

Wiberg, R., 2001. Energiförbrukning i massa-och pappersindustrin 2000. Swedish Forest Industries Federation, Stockholm.

Winston, W.L., 1994. Operations Research-Applications and Logarithms, third ed. Duxbury Press, Belmont, CA, USA. 